\title{
Access to Endodontic Care in North Carolina Public Health and Medicaid Settings
}

\author{
Steven L. Richardson, DMD
}

A thesis submitted to the faculty of the University of North Carolina at Chapel Hill in partial fulfillment of the requirements for the degree of Master of Science in the School of Dentistry (Endodontics).

Chapel Hill

2012

Approved by:

Ceib Phillips, BS, PhD, MPH

Asma Khan, BDS, PhD

Eric M. Rivera, DDS, MS 
(C)2012

Steven L. Richardson, DMD

ALL RIGHTS RESERVED 


\begin{abstract}
STEVEN L. RICHARDSON: Access to Endodontic Care in North Carolina Public Health and Medicaid Settings

(Under the direction of Dr. Ceib Phillips)

The purpose of this study was to investigate issues related to access to endodontic care in North Carolina for individuals who use dental public health resources such as public health clinics (PHC) or government sponsored reimbursement programs (Medicaid and NC Health Choice) in private dental practices (PPM). 1195 dentists were surveyed regarding frequency and type of endodontic conditions encountered, treatments provided, treatment techniques, referral patterns and perceived barriers to care. $79 \%$ report frequently encountering an endodontic condition but only 34\% report performing any type of definitive endodontic procedure. Lack of insurance was the greatest barrier to care with $89 \%$ considering it a moderate to major barrier, followed by cost of the endodontic treatment (87\%) and cost of the restoration following treatment (86\%). PPMs were more likely to consider cost and insurance a major barrier $(\mathrm{p}<.05)$. Treatment patterns and perceptions of barriers to care are different for PHCs and PPMs.
\end{abstract}


Dedicated to the dentists of North Carolina and across the country who selflessly serve their communities...one patient at a time. 


\section{Acknowledgements}

This work would not have been possible without the following assistance for which I am truly grateful:

Dr. Ceib Phillips, my thesis advisor, who believed in me and in this project

Dr. Asma Khan and Dr. Eric M. Rivera, my thesis committee members, for their advice and support throughout this process and throughout my training at UNC

Ms. Debbie Price and the staff at the UNC Orthodontics Research Lab for their assistance with survey preparation, scanning, and statistics

The staff and my fellow residents at the UNC Department of Endodontics who have supported me and given me a wonderful experience in North Carolina

The American Association of Endodontists Foundation and the UNC Department of Endodontics for their financial support

Most of all, I would like to thank my wonderful wife, Keri, who sacrificed willingly throughout this process and my children Hunter, Kailyn, Alton \& Kinley who mean everything to me. I am so blessed to have you all in my life. 


\section{Table of Contents}

Page

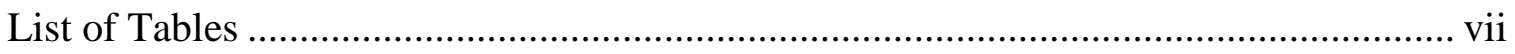

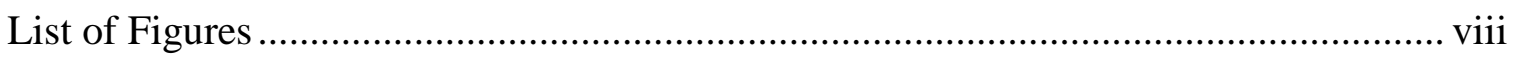

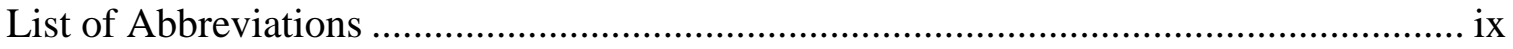

I. $\quad$ Section I - Literature Review ….............................................................

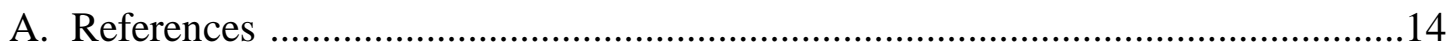

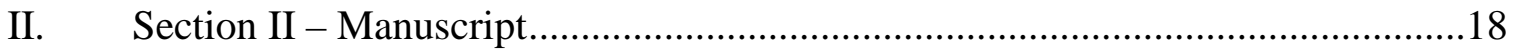

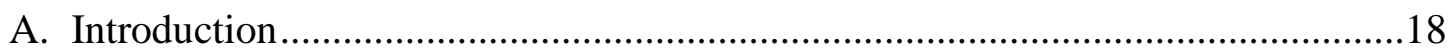

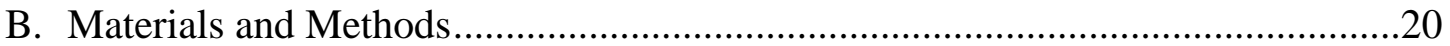

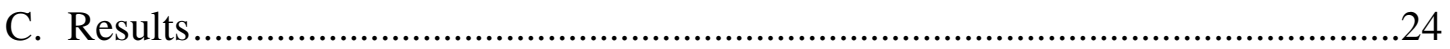

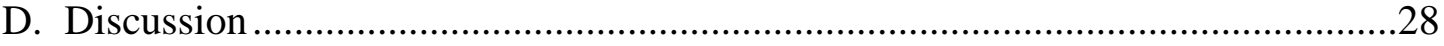

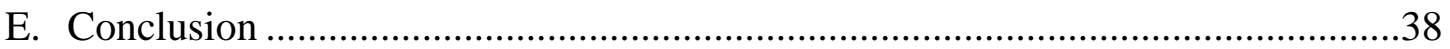

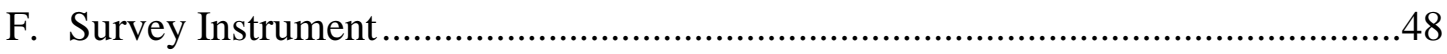

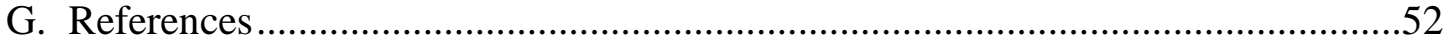




\section{List of Tables}

Table

Page

1. Table 1: Respondent Demographics

.40

2. Table 2: Logistic Regression - Respondent Demographics ................................42

3. Table 3: Respondent Percentages - Conditions and Procedures ..........................43

4. Table 4: Respondent Percentages - Referrals..................................................44

5. Table 5: Respondent Percentages - Endodontic Techniques ...............................44

6. Table 6: Logistic Regression - Conditions, Procedures, Referrals,

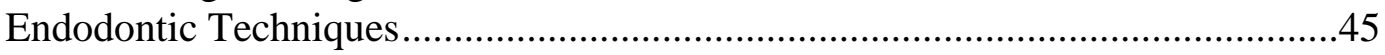

7. Table 7: Respondent Percentages - Barriers ..................................................46

8. Table 8: Logistic Regression - Barriers........................................................47 


\section{List of Figures}

Figure Page

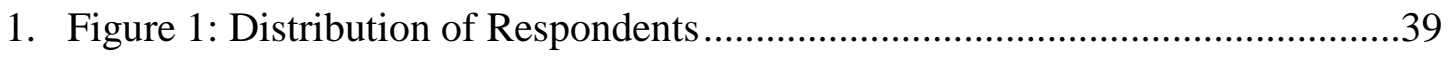

2. Figure 2: Respondent Demographics ........................................................41 


\section{List of Abbreviations}

$\begin{array}{ll}\text { AAE } & \text { American Association of Endodontists } \\ \text { ADA } & \text { American Dental Association } \\ \text { NC } & \text { North Carolina } \\ \text { NCBODEX } & \text { North Carolina Board of Dental Examiners } \\ \text { NCDS } & \text { North Carolina Dental Society } \\ \text { NSRCT } & \text { Non-surgical Root Canal Treatment } \\ \text { RCT } & \text { Root Canal Treatment } \\ \text { PHC } & \text { Public Health Dental Clinic } \\ \text { PPM } & \text { Private Practice Dental Office that accepts Medicaid or NC Health Choice } \\ \text { UNC } & \text { The University of North Carolina at Chapel Hill }\end{array}$




\section{Section I}

\section{Literature Review}

Access to health care in the United States has been a topic of interest for many years (1-2). The introduction of Medicare and Medicaid in the Social Security Act of 1965 expanded health care coverage to members of society who could not otherwise afford it (3). In 1997, the State Children’s Health Insurance Program (SCHIP) further expanded health care coverage to children of families living near poverty in the US (4). More recently, the Patient Protection and Affordable Care Act signed into US law March 23, 2010 by President Barack Obama, is another effort to improve access to health care for all. Like its predecessors, this latest reform, while focusing on the medical aspects of health care, also included some provisions for improving access to oral health care in the United States (5).

The Affordable Care Act of 2010 was not the first time access to oral health care was addressed at the national level (6). In 2000, Dr. David Satcher, the $16^{\text {th }}$ Surgeon General of the United States, put forth his landmark report: Oral Health in America - A Report of the Surgeon General (7). This document brought oral health to the forefront of the medical community by declaring "oral health is integral to general health" and that the two terms are not separate entities. It emphasized that while many dental public health programs, such as fluoridated water, had raised the oral health of the nation to levels better than ever before, oral diseases were still a "silent epidemic" affecting some of the nation's most vulnerable citizens. Perhaps the overriding message of the report on oral health was summarized in one 
sentence from the forward: "Despite the advances in oral health that have been made over the last half century, there is still much work to be done” (7).

The major findings of the Surgeon General's report include:

- "Oral diseases and disorders in and of themselves affect health and well-being throughout life.”

- "Safe and effective measures exist to prevent the most common dental diseases - dental caries and periodontal diseases.”

- "Lifestyle behaviors that affect general health such as tobacco use, excessive alcohol use, and poor dietary choices affect oral and craniofacial health as well.”

- "There are profound and consequential oral health disparities within the U.S. population.”

- “More information is needed to improve America's oral health and eliminate health disparities.”

- "The mouth reflects general health and well-being."

- "Oral diseases and conditions are associated with other health problems.”

- "Scientific research is key to further reduction in the burden of diseases and disorders that affect the face, mouth and teeth” (7).

Furthermore, the report emphasized that everyone has a role in improving and promoting oral health. The concluding chapter of the report issued a "Call to Action" which called on everyone involved to:

- "Change perceptions regarding oral health and disease so that oral health becomes an accepted component of general health.” 
- "Accelerate the building of the science and evidence base and apply science effectively to improve oral health.”

- "Build an effective health infrastructure that meets the oral health needs of all Americans and integrates oral health effectively into overall health.”

- "Remove known barriers between people and oral health services."

- "Use public-private partnerships to improve the oral health of those who still suffer disproportionately from oral diseases” (7).

The effects of unmet dental care are great. Dental caries is the most common chronic childhood disease in the US with nearly half of all 5-9 year old children and nearly $80 \%$ of all 17 year olds having experienced at least one cavity or filling (7-8). The number of work days missed due to acute dental problems approaches 2.4 million while routine dental visits cost 20 million days for US adults annually $(7,9)$.

These findings are not evenly distributed among all racial and socioeconomic groups, however. Poor children are nearly twice as likely to experience dental caries as their nonpoor counterparts and also more likely to have their dental disease go untreated (7). In addition, of the 51 million school hours that are lost annually due to dental related illnesses, poor children suffer 12 times as many restricted activity days than children from higher income families (7). Oral diseases often lead to pain, difficulty eating, speaking and concentrating (10).

In addition to lower income members of society, members of some racial and minority groups also suffer a disproportionate amount of dental disease. According to data from the Center for Disease Control and Prevention, non-Hispanic blacks, Hispanics, American Indians and Alaska Natives have the poorest overall health of any racial groups in 
the US (11). Among children, Mexican American and non-Hispanic blacks experience the greatest dental health disparities while adults in this group experience nearly twice as much untreated decay as non-Hispanic whites (11). These findings are not much different than a 1976 study regarding socio-cultural influences and attitudes towards dentistry. This early research found that black patients were more likely than whites to have decayed or unfilled teeth, fewer preventive services and a much later first dental encounter (12). Although much progress has been made in improving the oral health of the nation in the past 30 years, dental health disparities among races and socioeconomic groups still exist (13-14).

The American Dental Association has openly stated its position regarding access to oral health care (15). Among other things, they emphasize that oral health is essential for a healthy America emphasizing the role prevention plays along with oral health education. They also declare access to health care is key to good oral health stressing the need to bolster the public health infrastructure, improve reimbursement and incentives, and wisely allocate a limited number of financial resources. Finally, they encourage building on current successes by maximizing the resources of the private dental workforce and ensuring the services are provided by a properly trained workforce (15-16).

Since the publication of the Report on Oral Health, states, communities, dental societies and individual dentists have implemented various programs to answer this call to action (16-22). Several states have found a measure of success in addressing access to dental care issues. In 2011, the Centers for Medicare and Medicaid Services (CMS) published a report listing the accomplishments of eight states in developing programs designed to improve dental health for pediatric patients and improve utilization of dental services under Medicaid (22). The eight states reviewed (Alabama, Arizona, Maryland, Nebraska, North 
Carolina, Rhode Island, Texas and Virginia) each had unique, state specific methods of meeting the oral health needs of their population but they all shared some common initiatives that were instrumental to their success.

First, most of the states emphasized that success only came once partnerships were formed between State legislatures, State dental associations, provider groups and other interested parties. Having these good relationships and possibly a high profile individual willing to promote the cause for oral health brought a visibility to the oral health need as well as a promotion of the oral health resources for the population (22).

Next, a partnership with local dental schools, including loan repayment programs for students, was beneficial in improving access to care. Alabama, Nebraska, and North Carolina all operate clinics in underserved rural areas (22). Dental schools, especially those with advanced residency training programs, are uniquely positioned to address access to care barriers by having the ability to provide all levels of care often at reduced fees for patients (19). Students also often complete internships during their training further exposing students to the needs of the state in which they train. Several of the states in the report also provide state funded loan repayment for practitioners who either carry a large Medicaid patient load or practice outside of traditional urban areas of the state (22).

Not surprisingly, increased reimbursement in six States in the study led to increased provider participation and increased patient utilization. Rhode Island even noted that increasing reimbursement for only a portion of the population (children age 0-5 years) increased dentist participation and patient utilization for older children as well. According to the CMS report, however, many of the other strategies were as important as reimbursement for the improvement of access to care (22). 
Other state techniques included simplifying the administrative burden for providers in these programs, using grant monies to specifically serve vulnerable populations, increase education to families who use these services, targeting younger children with preventive care early or helping them find a dental home (22).

One recent example of innovation at the state level is the Kansas Initiative for New Dentists which will allocate $\$ 50,000$ per dentist to be distributed as loan repayment or practice start-up assistance for dentists who establish a practice in a "dental desert” which is described as an area where there are no other dentists for a 20 mile radius and where the practitioner agrees to designate 35\% of services to underserved groups and Medicaid patients (23). The first of these awards is set to be awarded in June 2012 with up to $\$ 150,000$ for 3 dentists allocated annually.

Within the state level, interested parties are also finding ways to improve access to dental care. For the past 10 years dental societies and dental offices have participated in Give Kids a Smile. What began as an outreach by a small group of dental volunteers has now grown into a national campaign that provides millions of dollars in free dental care to low income children annually with over 2000 sites participating in 2010 (19). Children aren't the only beneficiaries of such care. The America's Dentists Care Foundation sponsors “Mission of Mercy” clinics in 23 states for adults and children. These free events treat thousands of patients in weekend field clinics staffed by hundreds of dental volunteers. Patients in need usually wait in line for hours, often overnight, in order to receive dental care (24).

In addition to these great outreach programs, the ADA estimates that the majority of charitable dental care is performed quietly by private dental offices throughout the year, however, the association is quick to point out that charity is not a health care system (19). 
Despite all the efforts that are taking place, twelve years after the Surgeon General's "Call to Action,” barriers to dental care still exist for a sizeable portion of the population (16, 25-26). In 2007, the access to dental care issue was brought to our community doorsteps through the tragic case of Deamonte Driver (27). Deamonte was a 12 year old Maryland boy who developed a tooth infection, a condition readily treated by a root canal or an extraction. After failing to receive dental care when his Medicaid coverage lapsed, the infection spread to his brain. Two emergency brain surgeries and 6 weeks in the hospital failed to prevent his tragic death in February, 2007. Unfortunately, he is not the only person who has died from an odontogenic infection (28-29).

The barriers to dental care are many. Deamonte and countless other people must face barriers to care including lack of personal resources such as income and finances, shelter, transportation, or lack of adequate insurance. They must also deal with employment status, education level, age, place of residence, culture, language, immigration status, fear of dental treatment, negative attitudes towards oral health, difficulty finding and obtaining treatment by a dental provider, low reimbursement levels, and lack of an oral health education to adequately manage dental disease (16, 25, 30-31).

The state of North Carolina has a strong history of monitoring and addressing the oral health status of its residents. Currently, it has one of the most comprehensive oral health surveillance systems in the nation (32). Four times in the past 50 years the state has performed dental exams and interviews on subgroups of the state population to build an understanding of the state's overall oral health. These surveys took place in 1960-1963, 1976-1977, 1986-1987, and 2003-2004 (32). In addition, the North Carolina Oral Health Section has evaluated the treatment of dental caries for children age K-5 since 1996 (33), 
participates in the Behavioral Risk Factor Surveillance System for residents over age 18 (34), and also participates in the Child Health Assessment and Mentoring Program which measures access to dental care, dental utilization and outcomes for all children younger than age 17 (35). In addition, the state of North Carolina has implemented the "Into the Mouth of Babes” program where pediatric medical providers assist in screening and referring pediatric patients under age 3 for dental treatment (36-38).

Several populations in North Carolina have been studied regarding their oral health status, Medicaid dental utilization, and oral health care barriers. In a 2001 outcome study, Weintraub et al. reported on the dental experience of 15,438 North Carolina, Medicaidenrolled children from 1985 to 1992 . Their study found a significant benefit of sealing children's permanent $1^{\text {st }}$ molars as an effective means to prevent future caries-related restorative procedures on that tooth. This was especially true for children who had other filled teeth before sealant placement (39).

A 2002 study by Mofidi, Rozier and King involving caregivers of North Carolina Medicaid-insured children revealed that these caregivers perceived numerous access to dental care barriers for their children including difficulty finding providers, difficulty arranging an appointment among limited provider options, and difficulty arranging transportation. In addition, these caregivers further perceived barriers at the dental visit including lengthy wait times and perceived disrespectful or discriminatory attitudes towards them due to their public assistance status (40).

In 2003, Patton, et al. performed a prospective observational study of black and white, North Carolina HIV-positive patients regarding their perceived oral health status, treatment needs, dental care utilization and barriers to care. They found disparities among 
these two groups in symptoms, utilization and unmet dental need. The results of their study concluded that black patients in this population were significantly more likely to have unmet dental needs (41).

In 2010, Wells, et al. administered surveys to members of the North Carolina Lumbee Native American Tribe. Their results indicated that barriers to dental care among this group of patients include difficulty leaving work for dental treatments, cost of dental treatment, and a low oral health knowledge. They also identified an association between poor access to dental care and poor oral health-related quality of life for members of this North Carolina tribe (42).

Finally, a 2011 study of barriers to care for recently disabled patients in a North Carolina rehabilitation outpatient clinic reported that $16.6 \%$ of subjects reported difficulty receiving care since becoming disabled. Financial challenges were the greatest burden followed by physical accessibility issues (43).

While many barriers to general dental care exist for a sizeable portion of the population, these barriers may be greater when specialty care such as endodontics, orthodontics, oral surgery, or advanced patient management is necessary due to higher costs, higher complexity and fewer available providers (44-46). One study showed that among children with special health care needs, 20\% had unmet dental needs despite having private dental insurance. In addition, children with severe conditions such as cerebral palsy, autism, or Down syndrome experienced more complications to care and more difficulty finding a dentist willing to provide care (47). In a 2007 study regarding referrals for specialty periodontal treatment in England, perceived cost of treatment and number of specialist practitioners were considered significant barriers to referral and accessibility of specialist 
care (46). A study of caregiver perspectives regarding an institutionalized elderly population revealed that specialist services, including endodontics and implants, were considered the least important services for family members while denture care and pain relief were considered the most important services (48).

North Carolina dental specialist providers have also been studied regarding various aspects of access to dental care. A 2007 study investigated the participation level of North Carolina orthodontists in the NC Medicaid program as well as their perceptions of the program. Twenty four percent of their respondents were Medicaid providers with an additional 20\% who previously accepted Medicaid but did not any longer. Low reimbursement was considered a major barrier by all respondents while past Medicaid providers perceived broken appointments and patient tardiness as greater barriers than current providers (49). A 2008 study comparing Medicaid and equivalent non-Medicaid patients in nine North Carolina orthodontic practices revealed no difference between the two groups with regard to treatment procedures and outcome, patient compliance, broken appointments, broken appliances and oral hygiene (50). A 2010 "break-even” study of NC orthodontists and Medicaid reimbursement revealed that including Medicaid enrolled individuals as a $5 \%$ increase in number of patients in a practice is unlikely to have a negative financial impact on an orthodontic practice (51).

The American Association of Endodontists (AAE) has clearly stated its official position regarding access to dental care in the Access to Care Position Statement (52). The AAE recognizes that service is part of professional advancement and fulfillment for its members and pledges to work with the ADA and other organizations to improve access to quality dental care and to support its members in actions they take to do the same. 
Additionally, it recognizes that significant challenges prevent many individuals from accessing all levels of dental care. The current lack of adult coverage or poor reimbursement for endodontic procedures in government programs, such as Medicaid, is an additional barrier to the providers in their ability to improve access to care. Finally, the role of patient education and prevention is paramount in meeting access to endodontic care needs. The AAE strongly encourages its members to participate in outreach programs including Step Up!, Give Kids a Smile, and Missions of Mercy. In addition it recommends giving back individually - through volunteerism and charity services, collaboratively - as part of an outreach project or committee, educationally - by encouraging dental schools and residencies to accept Medicaid reimbursement and partner with other specialties such as pediatrics, and politically - by participating with a political action committee or candidate who advocates improving access to oral health care (52).

In July 2009, Dr. Gerald Glickman became president of the American Association of Endodontists. During his 2009-2010 term, he named “Access to Care” the theme of his presidency (53). This resulted in an outpouring of service and volunteerism by endodontists across the country, culminating in the Access to Care Project at the 2010 AAE Annual Session in San Diego, CA where 54 patients received approximately $\$ 85,000$ worth of free endodontic treatment (54). This project was repeated in 2011 in San Antonio, TX with 55 patients receiving approximately $\$ 80,000$ worth of care (55). Each of these projects further promoted the AAE ideal that "access to quality oral health care should extend to every American” (52).

Despite the many outreach projects regarding access to endodontic care in recent years, few studies exist relative to access to endodontic care. Kressin et al, studied the role of 
racial disparities in dental care and discovered that among their study participants in a Veterans Affairs dental clinic, black patients were less likely than white patients to receive a root canal (versus tooth extraction) while Asian patients were more likely than whites, despite all being eligible for continuing, comprehensive dental care (56). A study of the 1998 Iowa Medicaid population by Sweet, et al. compared service utilization of Medicaid users with patients who were privately insured with Delta Dental. This study showed that Medicaid users were twice as likely as Delta Dental patients to receive endodontic therapy and nearly 4 times as likely to have a tooth extraction (57). These findings may indicate that the Medicaid population experienced a lower overall oral health status at the time treatment was sought, despite being a younger overall patient population. It may also be indicative of a treatment delay due to barriers including waiting until dental problems become more severe, difficulty obtaining insurance coverage, or challenges finding a specialist able to provide treatment. Another report of Iowa Medicaid users between 1996 and 2000 revealed that children who had their $1^{\text {st }}$ molars sealed were less likely to require a future endodontic treatment or extraction on that tooth (58).

A radiographic study of Northern Manhattan elderly individuals evaluated, among other things, the presence or absence of periapical radiolucencies associated with root filled teeth as well as the appearance of the technical standard of root fillings (59). They found that among this underserved population, $37.5 \%$ of endodontically filled teeth had associated periapical radiolucencies and only a minority (26\%) of the root fillings were technically adequate based on radiographic appearance.

In a survey of 648 practicing Endodontists in 2010, 60\% of respondents considered endodontic treatment a “privilege” while only 9\% perceived it as a “right” (60). 
Additionally, a survey of 55 public health clinics in Ohio, Michigan, Indiana, Illinois, Kentucky and West Virginia evaluated the types of endodontic care provided and barriers encountered in these settings (61). Their results indicate that all of the endodontic care in these settings is provided by general dentists and $75 \%$ of the clinics did not perform molar endodontic treatments. Further, two major barriers were noted with $100 \%$ of respondents considering cost a barrier followed by patient preference at $67 \%$.

The definition of Endodontics is the diagnosis, prevention and/or treatment of apical periodontitis (62). This treatment option is essential to help patients maintain their teeth for a lifetime in health, function and esthetics. To our knowledge, no studies have been published regarding the role of endodontics in access to dental care in North Carolina public health and Medicaid settings. Such a study would provide important information for patients, providers and policy makers in North Carolina and could serve as a model for similar studies in different states and regions of the country. Such a study would also further fulfill the Surgeon General’s “Call to Action” from 2000 to raise the scientific evidence as we work towards breaking down barriers to care (7). 


\section{References:}

1. Marmor T, Oberlander J. The patchwork: Health reform, American style. Soc Sci Med 2011;72(2):125-128.

2. Davis K. Universal coverage in the United States: lessons from experience of the 20th century. J Urban Health 2001;78(1):46-58.

3. Berkowitz E. Medicare and Medicaid: the past as prologue. Health Care Financ Rev 2008;29(3):81-93.

4. Gibbons KH. Access to health insurance: State Children's Health Insurance Program. Issue Brief Health Policy Track Serv 2012:1-34.

5. Discepolo K, Kaplan AS. The patient protection and affordable care act: effects on dental care. N Y State Dent J 2011;77(5):34-38.

6. Kinlaw DH. Access to dental care: a historical review of medicaid eligibility growth and dental productivity decline. J Dent Educ 2001;65(9):849-860.

7. U.S. Department of Health and Human Services. Oral Health in America: A Report of the Surgeon General. Rockville, MD: U.S. Department of Health and Human Services, National Institute of Dental and Craniofacial Research, National Institutes of Health, 2000. 2000.

8. CDC. Oral Health - At a Glance 2011. National Center for Chronic Disease Prevention and Health Promotion - Division of Oral Health; 2011.

9. NCHS. National Center for Health Statistics. Current estimates from the National Health Interview Survey , 1996. Public Health Service;10(200).

10. Vargas CM, Arevalo O. How dental care can preserve and improve oral health. Dent Clin North Am 2009;53(3):399-420.

11. CDC. Disparities in Oral Health. 2009 [cited March 8, 2012]; Available from: http://www.cdc.gov/oralhealth/oral_health_disparities.htm

12. Strauss RP. Sociocultural influences upon preventive health behavior and attitudes towards dentistry. Am J Public Health 1976;66(4):375-377.

13. Dietrich T, Culler C, Garcia RI, Henshaw MM. Racial and ethnic disparities in children's oral health: the National Survey of Children's Health. J Am Dent Assoc 2008;139(11):1507-1517.

14. Jimenez M, Dietrich T, Shih MC, Li Y, Joshipura KJ. Racial/ethnic variations in associations between socioeconomic factors and tooth loss. Community Dent Oral Epidemiol 2009;37(3):267-275.

15. ADA. Improving Oral Health in America. 2009 March 9, 2009.

16. ADA. Breaking down barriers to oral health for all Americans: the role of workforce. J Calif Dent Assoc 2011;39(7):491-502. 
17. Bailit H, Beazoglou T, Demby N, McFarland J, Robinson P, Weaver R. Dental safety net: current capacity and potential for expansion. J Am Dent Assoc 2006;137(6):807-815.

18. Crall JJ. Oral health policy development since the Surgeon General's Report on Oral Health. Acad Pediatr 2009;9(6):476-482.

19. ADA. Breaking Down Barriers to Oral Health for All Americans: Repairing the Tattered Safety Net. A Statement from the American Dental Association 2011.

20. Borchgrevink A, Snyder A, Gehshan S. The Effects of Medicaid Reimbursement Rates on Access to Dental Care. Washington DC: National Academy for State Health Policy; 2008 March 2008.

21. ADA. State Innovations to Improve Access to Oral Health Care for Low Income Children: A Compendium Update. Chicago: American Dental Association 2005.

22. CMS. Innovative State Practices for Improving the Provision of Medicaid Dental Services: Summary of Eight State Reports: (Alabama, Arizona, Maryland, Nebraska, North Carolina, Rhode Island, Texas and Virginia). Centers for Medicare \& Medicaid Services (CMS); 2011.

23. Palmer C. Kansas Initiative Encourages 'Dental Desert" Practice; First Grant to be Awarded in June. ADA News 2012 March 5, 2012;Sect.

24. ADCF. America's Dentists Care Foundation - Missions of Mercy FAQs. 2012 [cited;

Available from: http://www.adcfmom.org/FAQs.html

25. Guay AH. Access to dental care: solving the problem for underserved populations. J Am Dent Assoc 2004;135(11):1599-1605; quiz 1623.

26. Edelstein BL, Chinn CH. Update on disparities in oral health and access to dental care for America's children. Acad Pediatr 2009;9(6):415-419.

27. Otto M. For Want of a Dentist. The Washington Post 2007 February 28, 2007; Sect.

28. Clarke JH. Toothaches and death. J Hist Dent 1999;47(1):11-13.

29. Aldous JA, Powell GL, Stensaas SS. Brain abscess of odontogenic origin: report of case. J Am Dent Assoc 1987;115(6):861-863.

30. Guay AH. Access to dental care: the triad of essential factors in access-to-care programs. J Am Dent Assoc 2004;135(6):779-785; quiz 797.

31. Robinson LA. Private sector response to improving oral health care access. Dent Clin North Am 2009;53(3):523-535.

32. Rozier RG, King RS. Defining the need for dental care in North Carolina: contributions of public health surveillance of dental diseases and conditions. N C Med J 2005;66(6):438-444.

33. NCDHHS. Annual K-5 Assessment of Oral Health. NC Department of Health and Human Services, Division of Public Health, Oral Health Section; 2005. 
34. NCDHHS. 2004 Behavioral Risk Factor Surveillance System Survey. Raleigh, NC: NC State Center for Health Statistics; 2005.

35. NCDHHS. Child Health Assessment and Monitoring Program (CHAMP). Raleigh, NC: NC State Center for Health Statistics; 2005.

36. dela Cruz GG, Rozier RG, Slade G. Dental screening and referral of young children by pediatric primary care providers. Pediatrics 2004;114(5):e642-652.

37. Close K, Rozier RG, Zeldin LP, Gilbert AR. Barriers to the adoption and implementation of preventive dental services in primary medical care. Pediatrics 2010;125(3):509-517.

38. Rozier RG, Stearns SC, Pahel BT, Quinonez RB, Park J. How a North Carolina program boosted preventive oral health services for low-income children. Health Aff (Millwood) 2010;29(12):2278-2285.

39. Weintraub JA, Stearns SC, Rozier RG, Huang CC. Treatment outcomes and costs of dental sealants among children enrolled in Medicaid. Am J Public Health 2001;91(11):1877-1881.

40. Mofidi M, Rozier RG, King RS. Problems with access to dental care for Medicaid-insured children: what caregivers think. Am J Public Health 2002;92(1):53-58.

41. Patton LL, Strauss RP, McKaig RG, Porter DR, Eron JJ, Jr. Perceived oral health status, unmet needs, and barriers to dental care among HIV/AIDS patients in a North Carolina cohort: impacts of race. J Public Health Dent 2003;63(2):86-91.

42. Wells PL, Caplan DJ, Strauss RP, Bell D, George M. An oral health survey of the Lumbee tribe in southeastern North Carolina. J Dent Hyg 2010;84(3):137-144.

43. Rouleau T, Harrington A, Brennan M, Hammond F, Hirsch M, Nussbaum M, et al. Receipt of dental care and barriers encountered by persons with disabilities. Spec Care Dentist 2011;31(2):6367.

44. Manski RJ, Moeller JF. Use of dental services: an analysis of visits, procedures and providers, 1996. J Am Dent Assoc 2002;133(2):167-175.

45. Rhodes KV, Bisgaier J. Limitations in access to dental and medical specialty care for publicly insured children. LDI Issue Brief 2011;16(7):1-4.

46. Sharpe G, Durham JA, Preshaw PM. Attitudes regarding specialist referrals in periodontics. Br Dent J 2007;202(4):E11; discussion 218-219.

47. Nelson LP, Getzin A, Graham D, Zhou J, Wagle EM, McQuiston J, et al. Unmet dental needs and barriers to care for children with significant special health care needs. Pediatr Dent 2011;33(1):29-36.

48. Matear D, Barbaro J. Caregiver perspectives in oral healthcare in an institutionalised elderly population without access to dental services: a pilot study. J R Soc Promot Health 2006;126(1):28-32. 
49. Im JL, Phillips C, Lee J, Beane R. The North Carolina Medicaid program: participation and perceptions among practicing orthodontists. Am J Orthod Dentofacial Orthop 2007;132(2):144 e115121.

50. Dickens S, Beane RA, Caplan DJ, Vann W, Jr. Comparison of treatment result and compliance between private practice Medicaid and non-Medicaid orthodontic patients--a brief communication. J Public Health Dent 2008;68(3):167-169.

51. Murdock JE, Phillips C, Beane R, Quinonez R. Break-even analysis of Medicaid vs fee for service in orthodontic practice: North Carolina as a case study. Am J Orthod Dentofacial Orthop 2010;137(3):334-339.

52. AAE. AAE Position Statement - Access to Care. Chicago, IL; 2010.

53. Glickman GN. President's Message - Access to Care: Bridging the Gap. Journal of Endodontics 2009;35(8):1163.

54. AAE. Volunteer Endodontists Save Teeth at First AAE Access to Care Event. AAE News Room 2010 May 7, 2010;Sect.

55. AAE. Free Root Canals Provided During AAE Access to Care Project. 2011.

56. Kressin NR, Boehmer U, Berlowitz D, Christiansen CL, Pitman A, Jones JA. Racial variations in dental procedures: the case of root canal therapy versus tooth extraction. Med Care 2003;41(11):1256-1261.

57. Sweet M, Damiano P, Rivera E, Kuthy R, Heller K. A comparison of dental services received by Medicaid and privately insured adult populations. J Am Dent Assoc 2005;136(1):93-100.

58. Bhuridej P, Damiano PC, Kuthy RA, Flach SD, Kanellis MJ, Heller KE, et al. Natural history of treatment outcomes of permanent first molars: a study of sealant effectiveness. J Am Dent Assoc 2005;136(9):1265-1272.

59. Chen C-Y, Hasselgren G, Serman N, Elkind MSV, Desvarieux M, Engebretson SP. Prevalence and Quality of Endodontic Treatment in the Northern Manhattan Elderly. Journal of Endodontics 2007;33(3):230-234.

60. Johnson MD, Mickel AK, Aminoshariae A, Montagnese TA. Access to Care in the United States and the Implications Within Endodontics - Root Canal Treatment: Is it a Right or Privilege? Journal of Endodontics 2010;36(3):551-584.

61. Morris D, Mickel AK, Aminoshariae A, Montagnese TA. Access to Care and Endodontics: Treatment Rendered in Public Health Clinics. Journal of Endodontics 2010;36(3):551-584.

62. Orstavik D, Pitt Ford T. Essential Endodontology: Prevention and Treatment of Apical Periodontitis. 2nd Edition ed: Wiley-Blackwell. 


\section{Section II}

\section{Manuscript}

\section{Introduction:}

Access to dental care is a topic of major interest (1-2). Significant challenges prevent some members of society from accessing all aspects of oral health care (3-4). These obstacles may be magnified in public health or rural health settings where resources are limited especially in cases where specialty dental care is required, as in endodontics (5).

The mission of dentistry is to help our patients maintain their natural teeth in optimum health, function and esthetics. Endodontics is involved in this mission by providing a means for a patient to maintain a tooth in a situation where it would otherwise be extracted. Thanks to modern techniques, dentistry is capable of providing treatment at the highest level of care (6). Thousands of dentists are practicing across the country who have graduated from some of the best educational facilities in the world, who are using the best dental materials available, and who are using the most advanced techniques. Despite all this, many members of society are unable to receive even basic dental care including preventive care or emergency care (7). This has sparked conversation in recent years regarding access to care. Barriers exist for many members of the community, but for patients requiring specialty care such as endodontics, these barriers are likely greater due to increases in complexity and cost as well as a decrease in the available number of qualified providers (8-11).

In 2000, the access to care discussion was brought to the forefront of the medical and dental world with the publication of "Oral Health in America: A Report of the Surgeon 
General” (1). In that report, Surgeon General, David Satcher MD, PhD, issued a call to action imploring the dental community to (among other things) 1) change perceptions regarding oral health, 2) apply science and evidence to improve oral health, 3) build a health infrastructure that meets the oral health needs of all Americans, 4) remove barriers to oral health and 5) develop public and private partnerships to improve oral health (1). Ten years later, Dr. Gerald Glickman DDS, MS declared “Access to Care” the theme of his presidency as he took over leadership of the American Association of Endodontists (12). This led to an outpouring of service and volunteerism from endodontists across the country culminating in a free endodontic clinic at the end of the year during American Association of Endodontists (AAE) annual session.

Significant improvements have occurred over the past 10 years. Several states including North Carolina, are developing creative and innovative ways to break down barriers to dental care (13-17). However, access to care is still a very real problem that people face every day. Deamante Driver, a 12 year old boy living in the Washington DC area, became known across the US after an untreated odontogenic infection spread to his brain and took his life (18). His tragic death could have easily been prevented with a root canal or an extraction. Unfortunately, this was not the first time a person died of an odontogenic infection (19-20).

Even though access to dental care was addressed specifically by the AAE in their Access to Care Position Statement, relatively few studies have explored this topic (21). Kressin et al, discovered that among patients in a Veteran's Affairs dental clinic, black patients were less likely than white patients to receive a root canal (versus tooth extraction) while Asian patients were more likely than white patients, despite all being eligible for 
continuing, comprehensive dental care (22). An Iowa study comparing dental treatments of Medicaid enrollees to patients with private dental insurance revealed that Medicaid enrollees were four times as likely to have a tooth extracted (23). A survey distributed to 55 public health dental clinics in Ohio, Michigan, Indiana, Illinois, Kentucky and West Virginia investigated provider perceptions of barriers to access to endodontic care for Public Health patients. This survey found that $100 \%$ of respondents considered cost a major barrier to endodontic care while only 25\% of the respondents reported performing any endodontic treatment (24).

The purpose of this study was to investigate issues related to access to endodontic care in North Carolina for individuals who use dental public health resources such as community dental clinics or government sponsored reimbursement programs (Medicaid and NC Health Choice) in private dental practices.

Our hypothesis was that fewer types and fewer numbers of endodontic procedures are being performed in public health settings than in private practice general dentist offices accepting Medicaid or NC Health Choice reimbursements. We also hypothesized practitioners would perceive the high cost of specialty care and the lack of endodontic specialist providers locally to be major barriers to care.

\section{Materials and Methods:}

In order to investigate North Carolina dentists' endodontic practice trends over the previous 12 months and their perception of the barriers to access to endodontic care, a survey was designed to investigate five areas of interest: 1) The type and frequency of endodontic conditions encountered by the provider, 2) the type and frequency of endodontic procedures performed, 3) the type and frequency of endodontic referrals provided, 4) the type of 
endodontic techniques and materials used by the provider, and 5) the dentists’ perception of barriers to the provision of endodontic care. The remaining questions in the survey pertained to respondent demographics. This study design was approved by the University of North Carolina (UNC) Biomedical Institutional Review Board of the Office of Human Research Ethics.

The survey instrument was created in electronic format using Qualtrics Software (Qualtrics Provo, UT) under a license agreement with the University of North Carolina, School of Dentistry. All responses to the electronic survey were recorded in the Qualtrics program to maintain security and respondent confidentiality. A duplicate survey in paper format was created using Teleform (Cardiff Software, Vista, CA) for any respondents for whom an email address was not located or who failed to respond to the electronic survey. Paper responses were individually coded to a linkage file which was kept in a separate location to maintain confidentiality. Paper responses were previewed to ensure proper completion of the survey and then scanned and recorded electronically to eliminate entry error. Prior to distribution, both the electronic and paper surveys were pilot tested for clarity, ease of completion and accuracy of the electronic links by a pilot group of general dentists and endodontic specialists.

The target population for this survey consisted of licensed, active North Carolina dentists currently working in a "public health or Medicaid setting." For the purposes of this research, these settings included: 1) Any public health dental clinic such as a Community Health Center, Community Dental Center, Federally qualified health center (FQHC) or FQHC look-a-like, 2) Any special care health center including women \& children dental clinics, migrant care, HIV clinics, homeless shelters, Mobile Van, Indian Health Service, 
VA, Hospital clinic, etc, and 3) Any private practice dental office that accepts the government sponsored insurance (Medicaid, NC Health Choice for children), or a sliding fee scale reimbursement.

Respondents were excluded if they were retired or not actively practicing dentists, did not practice in North Carolina, did not work in a public health setting, or did not accept Medicaid, NC Health Choice or sliding fee reimbursement in their private practice. They were also excluded if they did not consent to participate in the survey, did not return a legible survey, or were recognized as a specialist provider by the North Carolina Board of Dental Examiners (NCBODEX) including Oral Surgeon, Orthodontist, Periodontist, Prosthodontist, Oral Pathologist, and Oral and Maxillofacial Radiologist as the limitations of these practices would not include endodontic treatment.

Potential respondents were identified using the NC Medicaid and Health Choice provider lists (Sept 2010) and the dental category of the US Public Health Service.

Additionally, public health clinics registered with Medicaid and NC Health Choice, the North Carolina Community Health Center Association, and US Human Resources and Services Administration (HRSA) were identified. Many listings were registered by the business name rather than the individual provider name, especially in the case of private practice offices with multiple locations. In addition, public health clinics were registered by the clinic name or, occasionally, by the dental director's name. Rarely was each provider registered individually in these locations. In instances when no provider was specifically identified, an internet search was conducted or the offices were phoned directly to obtain the name of the providers at each location. 
After the master list of North Carolina public health and Medicaid dental providers was provided, duplicate entries and providers who were identified as specialists listed in the exclusion criteria were removed. The remaining providers were compared to the NCBODEX master list of active licensees as of June 1, 2011, to confirm they met the inclusion criteria. Mailing addresses from the NCBODEX were used as these are required to be kept updated as a condition of licensure. The email addresses used were those registered with the North Carolina Dental Society membership list which is updated annually. The master list consisted of 1228 individual providers including 564 providers with a valid email address.

The survey was distributed using the Salant and Dillman method including at least 3 contacts per respondent for each of the survey formats used (25). All providers with a valid email address were sent an email, using Qualtrics, informing them of the upcoming survey opportunity. The next day each of the 564 respondents received a cover letter with instructions, consent information, and a link to the live survey. After 2 weeks, a reminder email with survey link was sent to any non-respondents as identified by Qualtrics. Two weeks after the $1^{\text {st }}$ reminder, a final reminder email with survey link was sent to any remaining non-respondents and the survey remained live for 4 additional weeks.

While the electronic survey was active, postcards were distributed by mail to the remaining 631 respondents who did not register an email address with the NCDS. These postcards were identical to the initial Qualtrics email informing respondents of the upcoming survey opportunity. One week following the postcard, a cover letter, informed consent and paper survey were mailed to each respondent - identical to the Qualtrics version distributed earlier. After 4 weeks, the electronic survey was closed and all non-respondents to the electronic survey and all non-respondents to the paper survey received another invitation to 
participate in the standard mail with a cover letter, informed consent and a duplicate copy of the survey. Responses were collected for an additional 4 weeks at which time data collection was closed.

The responses obtained through Qualtrics and the scanned paper responses were combined into a master data set. The statistical analysis was performed using PASW software version 18 (SPSS inc, Chicago, IL). Descriptive statistics identified proportions and percentages of the endodontic variables included in the survey, correlations were noted using bivariate analysis (Chi-square $\mathrm{p}<.05$ ) followed by binomial logistic regression at a $95 \%$ confidence interval to analyze the data. For analysis, respondents were grouped into bivariate categories based on demographics. In addition, the four survey responses (at least once per week, at least once per month, less than once per month, never) were combined for analysis into two groups - "Frequently" (At least once per week and at least once per month) and "Rarely to Never" (less than once per month and never). Likewise, the 5 categories regarding endodontic barriers (Significant barrier, Moderate barrier, Mild barrier, Not a barrier, No Opinion) were also combined into two groups - "Moderate to Major Barrier" (Significant barrier and Moderate barrier) and “Not a Major Barrier” (Mild barrier, Not a barrier, No opinion).

\section{Results:}

\section{Distribution and Response Rate:}

The survey was distributed to 1228 individual dental providers in either electronic or paper format. No email surveys were returned undelivered, however, 33 paper surveys were returned as undeliverable. Of the remaining 1195 responses, 546 surveys were returned (45.7\% response rate) of which 479 met the inclusion criteria and were used for statistical 
analysis. Respondents were well distributed across the state representing 179 unique towns and cities (figure 1).

\section{Respondent Demographics}

Respondent demographics are reported in Table 1. Respondents were grouped based on practice type, practice location and year of graduation (Figure 2). The majority of respondents practiced in private practices that accept Medicaid (83\%) and were in rural or small town settings (65\%). Additionally, most of the respondents graduated prior to the year 2000 (73\%), were male (74\%), and identified as white or Caucasian (76\%).

A significantly higher percentage of females ( $p=.001$ Odds Ratio (OR): 2.3) and minority race ( $p=.003$ OR: 2.1) respondents graduated in the year 2000 or later than their white, male counterparts. Females were also significantly more likely to be in a PHC than a PPM ( $\mathrm{p}=.001$ OR: 2.6). UNC Graduates were significantly more likely to practice in a rural setting than out of state graduates ( $\mathrm{p}=.01 \mathrm{OR}$ : 1.7). Out of state graduates, however, were significantly more likely to be in a PHC than a UNC graduate $(\mathrm{p}<.001$ OR: 3.4 logistic regression table 2).

\section{Endodontic Conditions and Treatments}

Table 3 displays the frequency with which respondents encountered various endodontic conditions as well as the frequency with which respondents provided endodontic treatments on these patients. Caries to the pulp was the most frequently encountered endodontic condition with $78.7 \%$ of respondents reporting that they encountered it at least once per month in the preceding 12 months followed by irreversible pulpitis (76.1\%) and pulpal necrosis (70.3\%). 
PHCs were significantly more likely to encounter an endodontic condition than a PPM (p<.05 OR: 2.1-4.7). Likewise, respondents in rural settings were significantly more likely to encounter caries to the pulp ( $\mathrm{p}=.04$ OR: 1.7) or irreversible pulpitis ( $\mathrm{p}=.02$ OR: 1.7) than respondents in an urban setting (logistic regression table 6).

The indirect pulp cap procedure was the most frequently performed treatment with 59.7\% reporting that they performed it at least once per month in the preceding 12 months. Direct pulp cap followed (43.9\%) and then pulpotomy (34.8\%). 33.8\% of respondents reported that they frequently (at least once per month) performed anterior non-surgical root canal procedures followed by $21.3 \%$ for premolars and $17.4 \%$ for molars (Table 3 ).

Graduation year was the most significant explanatory variable for definitive endodontic procedures performed. Graduates after 2000 were significantly more likely to perform an indirect pulp cap ( $\mathrm{p}<.01$ OR: 1.8) or pulpotomy ( $<<.001$ OR: 2.2 ) as well as an Anterior ( $\mathrm{p}<.001$ OR: 3.1), Premolar ( $<<.001$ OR: 3.3) and Molar Root Canal ( $<.001$ OR: 2.97). PHCs were significantly more likely to perform palliative endodontic treatments including indirect pulp cap ( $\mathrm{p}=.001$ OR: 2.8), pulpotomy ( $\mathrm{p}=.001$ OR: 2.5), Pulpal debridement ( $\mathrm{p}<.05$ OR: 1.8) as well as premolar root canals ( $\mathrm{p}<.01$ OR: 2.2 table 6).

\section{Endodontic Referrals}

A local endodontist was the most frequent referral made with $23.3 \%$ of respondents reporting that they refer at least once per month (table 4 ). $8.7 \%$ of respondents reported that they frequently refer to the UNC School of Dentistry. Both PHCs and graduates after 2000 were significantly more likely than their counterparts to refer to both the endodontist or to the UNC school of dentistry ( $<<.05$ table 6$)$.

\section{Endodontic Techniques}


Many respondents (43.6\%) reported using a combination of hand and rotary instrumentation for endodontic procedures (table 5). In addition, 40.7\% reported using an electronic apex locator and 51.8\% had digital radiography in their offices. $40.7 \%$ of respondents reported using a lateral condensation technique to obturate the root canals while $21.7 \%$ reported using no endodontic materials or techniques whatsoever.

Logistic regression (table 6) indicated that graduation year was the most significant factor in endodontic technique and materials used. Of the respondents that did perform endodontic procedures, graduates after the year 2000 were significantly more likely to use combination hand and rotary instrumentation ( $\mathrm{p}<.001$ OR: 2.8), electronic apex locators $(\mathrm{p}<.001$ OR: 2.7) and digital xrays ( $<<.001$ OR: 4.4). In addition, they were significantly more likely to utilize a thermoplastic device such as obtura (Obtura Spartan Endodontics, Algonquin, IL) or calamus (DENTSPLY Tulsa Dental Specialties, Tulsa, OK) for completing their endodontic procedures ( $\mathrm{p}=.035$ OR: 1.9). Graduates 1999 and earlier were significantly more likely to respond that they did not use any endodontic techniques for treatment in these settings ( $<$.001 OR: 3.1 table 6).

\section{Endodontic Barriers}

Lack of insurance coverage was the greatest barrier to care with $89.2 \%$ of respondents considering it a moderate or major barrier, followed by the cost of the endodontic treatment (87.4\%) and cost of the final restoration (85.5\% table 7). Lack of Endodontists who accept the patient's insurance was fourth with $80.4 \%$ of respondents perceiving it a moderate or major barrier. Lack of training in dental school was least likely to be considered a barrier at 16.3\% with language and culture differences next at 18.2\% (table 7). 
PPMs were significantly more likely to consider lack of insurance ( $\mathrm{p}=.022$ OR: 2.3) and cost of endodontic treatment ( $\mathrm{p}=.033$ OR: 2.0) major barriers, while PHCs were significantly more likely to consider transportation ( $\mathrm{p}=.001$ OR: 2.6), language and culture ( $p<.001$ OR: 3.1), dental history ( $\mathrm{p}=.05$ OR: 1.8) and patient preference ( $\mathrm{p}=.001$ OR: 3.0 ) major barriers. Additionally, rural respondents were significantly more likely to consider transportation ( $\mathrm{p}=.003$ OR: 1.9), dental IQ ( $\mathrm{p}=.034$ OR: 1.6), dental history ( $\mathrm{p}=.025$ OR: 1.6) and patient preference ( $\mathrm{p}=.011$ OR: 1.7) major barriers. Female respondents were significantly more likely to perceive lack of training in dental school as a major barrier ( $p=.022$ OR: 1.9) while graduates after 2000 were more likely to consider lack of insurance a major barrier ( $\mathrm{p}=.045$ OR: 2.3 table 8$)$.

\section{Discussion:}

The 1195 individual Medicaid and public health dental providers across North Carolina represent $28 \%$ of all active North Carolina dentists, and 32\% of all North Carolina general dentists, dental public health specialists, pediatric dentists and endodontists. This is higher than the US Health Resources and Service Administration (HRSA) estimate that, nationally, 20\% of all active dentists are registered Medicaid providers (26). Of the 479 valid responses received, 8 of the respondents were in special health care settings that did not accept Medicaid or NC Health Choice (NCHC) reimbursement. This is fitting for a state that was praised for having one of the most comprehensive oral health surveillance systems in the nation (27).

Most of the respondents in our survey were rural or small town private practitioners who accept Medicaid rather than dentists in public health locations. This is interesting because it demonstrates the role these providers have in service to the community. The 
surgeon general's report, the ADA and the AAE all recommend utilizing the existing private practice workforce to break down access to care barrier $(1,3,21)$. Although nearly every respondent accepted Medicaid in their practice, no attempt was made to determine what percentage of their active patients used Medicaid or NC Health Choice reimbursement. Some practitioners may treat several patients each week who use Medicaid while others may see only a few each year.

Medicaid is a health insurance program for low income individuals and families who cannot afford health care costs. While managed by individual states, it is jointly funded at the federal and state level. All Medicaid programs provide coverage for children while coverage levels and decisions for adults are left up to the state. NC Health Choice is health coverage specifically for North Carolina children ages 6 through 18 in families that do not qualify for Medicaid but still are not able to afford health care premiums (28). As of October 2011, medical and dental providers who enroll as an NC Health Choice provider must also enroll as a Medicaid provider.

NC Medicaid and NC Health Choice provide comprehensive but slightly differing endodontic dental coverage. Both provide coverage for a therapeutic pulpotomy, as well as nonsurgical, anterior root canals for all patients. Likewise, they both provide coverage for a direct amalgam or composite restoration following endodontic treatment. NC Medicaid further provides coverage for individuals under age 21 for premolar and molar nonsurgical root canals while NC Health Choice limits that coverage to only the $1^{\text {st }}$ molar of individuals under age 19. Both programs also provide coverage for stainless steel posterior crowns for children. Medicaid will cover an apicoectomy or apexification for anterior teeth regardless of age while NC Health Choice omits this coverage. This coverage by NC Medicaid and 
Health Choice (especially adult coverage) is far more comprehensive than most states in the nation (29).

A sliding fee schedule is a matrix whereby uninsured patients can pay a percentage of the dental fees based on income. This tool was overwhelmingly used by PHCs in our study versus PPMs (70.5\% vs 5.9\%) and has the benefit of allowing a patient to receive a treatment that is not otherwise covered and would otherwise be unaffordable. Sites using a sliding fee schedule are often subsidized by outside funding sources to offset the discounted fees. This is highly unlikely in a private practice model which may have limited the treatment options for some patients in these settings.

Graduation year was the most significant factor in whether or not endodontic procedures were provided by respondents in our survey with recent graduates more likely than older graduates to provide treatments. It was interesting to note that gender and race were both associated with graduation year. A significantly higher proportion of graduates after the year 2000 were women and minorities compared to graduates before the year 2000 . This may explain why a significantly higher percentage of minority providers and a higher but not statistically significant percentage of female providers reported performing root canal procedures on anterior, premolar and molar teeth.

The dental school attended by the respondents did not significantly affect the provision of any endodontic treatment, however, it did significantly affect the respondents practice location in the state with UNC graduates significantly more likely than non-UNC graduates to practice in a rural or small town setting ( $71 \%$ vs 57\%). According to HRSA statistics in 2012, 66 of North Carolina's 100 counties are designated as Dental Health Profession Shortage Areas making a provider's willingness to practice in one of these areas a 
major step towards breaking down barriers to care. University administrators and policy makers may want to keep this in mind when making decisions about the number of in-state and out-of-state dental students and residents to accept as they search for innovative ways to meet the access to care need.

\section{Endodontic Conditions, Endodontic Treatments, and Endodontic Techniques}

The results of this study indicate that in North Carolina public health and Medicaid settings there is a disparity between the type and frequency of conditions encountered and the type and frequency of treatments provided. Although a vast majority of respondents reported frequently encountering a dental condition where endodontic treatment would be an appropriate treatment option, the vast majority of respondents rarely or never perform these services. A limitation of this study was that the survey did not identify and compare these percentages in PPMs with the same conditions and treatments for privately insured or feefor-service patients (ie, non-Medicaid users) in the same offices. Nevertheless, our results indicate that there is currently an unmet need for endodontic treatments for patients in North Carolina PHCs and PPMs, and this need is higher in the rural regions of the state.

PHCs were significantly more likely to perform palliative or emergency treatments than PPMs. Direct and indirect pulp caps, are essentially attempts to prevent a root canal, despite the limited evidence to their benefit, especially in cases of a carious pulp exposure (30). This could be related to the fact that PHCs were more likely to encounter the conditions, but still unable to provide definitive treatment. Interestingly, of the $21 \%$ of respondents who reported performing premolar root canals frequently, PHC dentists were significantly more likely than PPM dentists to do so. One potential explanation for this is the fact that premolar RCTs are not a covered service under NC Health Choice which many 
PPMs would accept. Premolar RCTs would, however, be covered under NC Medicaid for patients under age 21 and on a sliding fee schedule (which PHCs are more likely to have available) for uninsured patients or Medicaid patients age 21 and older.

Many factors may influence the finding that graduation year was the strongest indicator of the provision of definitive endodontic treatments in the form of an anterior, premolar or molar root canal. Certainly, advancements in the field of endodontics over the decades have made root canal treatments a more predictable and successful treatment option. Contemporary endodontic training includes the use of an apex locator, digital x-rays, nickel titanium rotary instrumentation and thermoplastic obturation techniques. Each of these devices was used by a significantly higher percentage of graduates after the year 2000 than those graduating in 1999 or earlier.

Dental offices across the nation have also been affected by the slow economy in recent years. New dentists, who may have heavy debt loads without the benefit of years of practice experience and a large patient base, may feel more pressure to perform endodontic treatments versus more established dentists.

Based on the results of our survey, true endodontic specialty treatments such as apicoectomy, apexification, pulpal regeneration, and endodontic retreatments were almost never performed. This indicates that while the potential to meet the routine endodontic needs of the public health community is in place, the ability to meet their specialty needs is lacking.

A limitation of this study was that the survey did not specifically ask how frequently an extraction was performed on a restorable, endodontically involved permanent tooth. As the usual alternative to endodontic treatment is tooth removal, it was most likely a frequent occurrence. 


\section{Endodontic Referrals}

The American Association of Endodontists (AAE) estimates that general dentists refer about half of their root canal cases to an endodontic specialist (31). In our study, however, only $23 \%$ of respondents reported frequently referring to an Endodontist. Of those that did, public health dentists were significantly more likely. Through the course of this research project, 4 endodontists were identified in the state of North Carolina who qualified for inclusion in the study. None of these individuals, however, were identified as Endodontic specialists on the NC Medicaid dental provider list. Three were mistakenly identified as Oral Surgeons and one was excluded all together. Therefore, unless a referring dentist knew personally that an endodontist accepted Medicaid, there would be no way to determine this.

This presents a unique challenge to referring dentists. If they encounter a patient with Medicaid or NC Health Choice coverage who needs an endodontic treatment that they are not comfortable performing, there are very few endodontic specialists in North Carolina registered to accept the patient's insurance. The remaining options for both patient and dentist are limited. Certainly a patient is welcome to go to any endodontist and receive treatment at their usual and customary fee. The fee for a single molar root canal, however, may represent the entire monthly income for a family that qualifies for Medicaid. The dentist may attempt to delay the need for a root canal using an indirect pulp cap as seems to be the trend in our study, although the biology of this technique indicates that it is simply delaying the inevitable (30). An endodontic specialist may elect to treat the case at a discounted rate or as a charitable act, however, charity is not a health care system (32). Lastly, the patient and provider may feel like there is no other option but to extract the tooth. This treatment 
choice brings its own consequences including loss of function and esthetics as well as increased future cost if the decision to replace the missing tooth is made later.

Only 8.7\% of respondents reported that they frequently referred patients for endodontic treatment to the UNC School of Dentistry. This is despite the fact that the University accepts Medicaid and NC Health Choice reimbursement, has discounted fees for individuals without dental insurance and can perform the entire spectrum of endodontic treatment. Certainly the distance some patients would be required to travel to receive treatment at UNC would be a challenge, but some of the respondents who chose to contact the principle investigator during the course of this study did not even realize that UNC was an option. Potentially, a University, especially one with an Endodontic residency program, is well positioned to address access to endodontic care issues.

\section{Endodontic Barriers}

North Carolina has one of the most comprehensive Medicaid coverage programs in the country. While many states offer little or no adult Medicaid dental benefits, NC Medicaid provides coverage for adults in many areas of dentistry, including emergency endodontics (pulpotomy) and definitive anterior endodontics. NC Medicaid even provides coverage for a restoration post treatment although not a full coverage crown. Despite the level of coverage, reimbursement rates to the dentist are low and were further lowered at the end of 2011 in the state budget. Unfortunately, this study did not gain information from respondents regarding their satisfaction with the reimbursement rate and the role that plays in access to endodontic care.

Not surprisingly, cost and insurance issues were perceived as moderate to major barriers by the highest percentage of respondents. Because qualification for Medicaid and 
NC Health Choice are income dependent, it is very reasonable that cost of the treatment for non-covered items such as premolar and molar root canals for adults, full coverage crowns after endodontic treatment, etc. is the most prominent barrier. Even for covered services, ie anterior root canals, the low reimbursement rate may make the cost of endodontic treatment too expensive for the dentist if the reimbursement does not meet the overhead costs of performing the procedure.

A study of six states demonstrated that increasing the reimbursement rates of Medicaid covered services to a level near equivalent to private insurance has a positive effect on access to care by enrolling more dentists into the program and encouraging the dentists to treat more patients (33). Raising the reimbursement level is only one factor, however. The fact that PPMs were more likely to perceive cost and insurance as major barriers versus PHCs who were more likely to face issues with transportation, language and patient preferences indicates that there are many barriers to be overcome by all parties involved. More than half of the respondents considered patient factors such as dental IQ (a patient's lack of appreciation for maintaining their natural teeth) or patient preference (a patient prefers an extraction to a root canal) to be moderate to major barriers. Our survey did not ask dental public health patients their feelings regarding these same barriers, however. Historically, North Carolina had a high prevalence of dental disease, but these trends have reduced over the decades $(27,34)$. It is possible, that this negative stereotype regarding the oral health of North Carolinians may have an influence in the treatment options providers present. This is certainly a barrier that each individual provider can work towards breaking down by thoroughly explaining and educating our patients on the risks, benefits, and potential future costs of each treatment decision whether it be a root canal or an extraction. 
Overwhelmingly, respondents did not consider language and culture differences and dental school training to be barriers to care. This is encouraging, as it demonstrates that dental schools are doing a good job in preparing providers who can not only perform adequate dentistry but also relate to individuals from increasingly diverse backgrounds. This also brings up the conflicting information that even though the majority of respondents feel adequately trained to address the endodontic conditions they encounter in practice, the majority are still not providing endodontic treatments to patients in public health and Medicaid settings.

Because many barriers are involved in access to endodontic care, removing just one barrier will not likely correct the situation. Rather, attempts to break down barriers to care should address as many barriers as possible. There are many ways an individual provider can work to break down barriers to care. While enrolling more North Carolina endodontists in Medicaid and NC Health Choice may seem like an obvious solution, the unmet endodontic needs in North Carolina do not appear to require an endodontic specialist. Anterior Root Canals, a procedure tested on the CITA Board Exam for licensure in the state, were rarely if ever performed by two-thirds of the respondents. Even if all the endodontists in North Carolina were to enroll as Medicaid providers, there are more than double that number of general dentists already enrolled as Medicaid providers who responded that they rarely to never perform an anterior root canal. Furthermore, true endodontic specialty treatments are not covered by these reimbursement programs with the exception of anterior teeth apicoectomy and pulpal regeneration. Activating the general dental providers who are already in the system through increased reimbursement rates or other methods may be a more realistic goal. 
Teaching or volunteering part time at a dental school or endodontic residency program may be one of the best ways an individual endodontist can address access to endodontic care issues. In this environment, an endodontist will play a key role in getting appropriate endodontic treatment to this population in need. Dental training programs are unique in that they can address financial and insurance issues due to their fee structure, training and treatment issues, as well as patient issues like fear and dental IQ since students and residents generally spend a considerable amount of time with their patients, a luxury limited in a private practice or busy public health clinic. By volunteering in this environment, a provider can work towards addressing the need without the burden of administrative Medicaid paperwork and with minimal disruption to their private practice.

Dental schools are often positioned in geographic areas of major need. One disadvantage of a school is its lessened ability to meet the needs of individuals living far away from the school. Certainly, many patients are unable to drive several hours or make multiple visits to a dental school for treatment. By implementing externships and outreach programs, a dental school or an endodontic residency can further address some of these geographic and transportation barriers.

Another way an endodontist can work towards breaking down barriers to endodontic care while addressing the issue of transportation and location is by volunteering at an outreach clinic such as a Mission of Mercy event or Access to Care Project at an AAE annual session. These projects have the ability to take the providers to the population in need, thus minimizing the geographic restrictions people face.

Access to endodontic care is a major issue with multiple levels. Policy makers, providers and patients need to work together to find solutions and remove barriers a little at a 
time. While other states may face similar issues, caution should be used when applying our findings to dental populations elsewhere in the country due to the differing needs, policies, geography and resources of individual states.

\section{Conclusion:}

In conclusion, based on the results of our study, in North Carolina public health and Medicaid settings:

- The frequency of endodontic treatments provided does not match the frequency with which endodontic conditions are encountered.

- Respondent year of graduation from dental school was the greatest indicator for the provision of root canal therapy with graduates after the year 2000 significantly more likely to perform definitive endodontic procedures and to use contemporary endodontic techniques and equipment.

- Graduates after the year 2000 and PHCs were more likely to refer a patient for specialty endodontic treatment.

- Insurance issues and cost were considered moderate to major barriers to care by the greatest percentage of respondents.

- Treatment patterns and perceptions of barriers to endodontic care are different for dentists in public health clinics versus those in private practice offices that accept Medicaid or NC Health Choice reimbursement.

This study was funded by a grant from the American Association of Endodontists Foundation and by the UNC Department of Endodontics. 
Figure 1: Distribution of Respondents

North Carolina towns with at least one survey respondent -179 towns

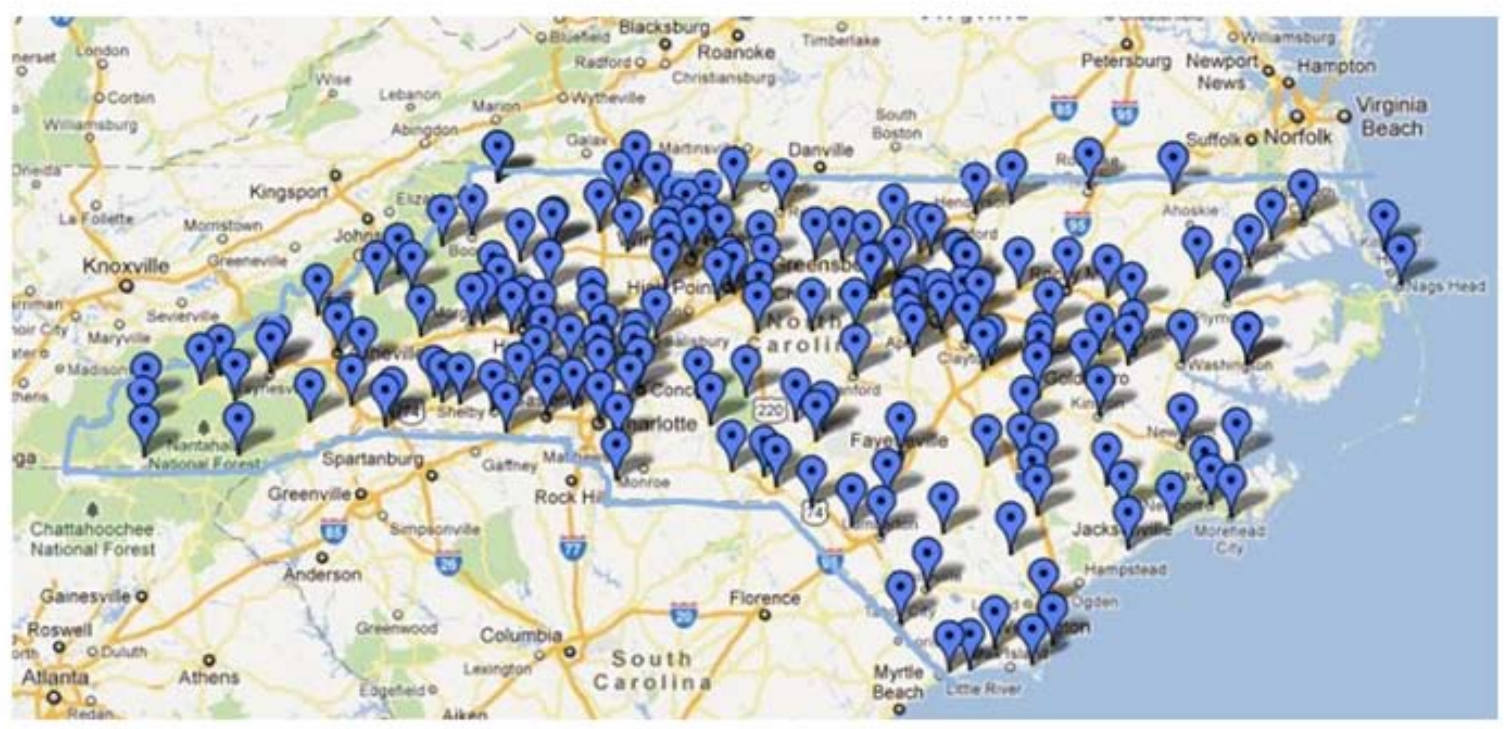


Table 1: Respondent Demographics $\quad \mathrm{N}=479$

\begin{tabular}{||l|c|c||}
\hline \hline Practice Type & $\mathrm{n}$ & $\%$ \\
\hline Public Health Clinic & 78 & 16.8 \\
\hline Private Practice - Medicaid & 387 & 83.2 \\
\hline Total & 465 & \\
\hline Did not Respond & 14 & \\
\hline \hline Location & $\mathrm{n}$ & $\%$ \\
\hline Rural or Small Town Setting & 304 & 65.2 \\
\hline Suburban or Urban Setting & 162 & 34.8 \\
\hline Total & 466 & \\
\hline Did not Respond & 13 & \\
\hline \hline Year of Graduation & $\mathrm{n}$ & $\%$ \\
\hline 1999 or Earlier & 345 & 72.5 \\
\hline 2000+ & 131 & 27.5 \\
\hline Total & 476 & \\
\hline Did not Respond & 3 & \\
\hline \hline Dental School & $\mathrm{n}$ & $\%$ \\
\hline UNC School of Dentistry & 272 & 57.6 \\
\hline Other & 200 & 42.4 \\
\hline Total & 472 & \\
\hline Did not Respond & 7 & \\
\hline \hline Advanced Training & $\mathrm{n}$ & $\%$ \\
\hline No advanced certificate/degree & 297 & 63.1 \\
\hline Has completed advanced certificate/degree & 174 & 36.9 \\
\hline Total & 471 & \\
\hline Did not Respond & 8 & \\
\hline \hline Gender & $\mathrm{n}$ & $\%$ \\
\hline Male & 346 & 74.4 \\
\hline Female & 119 & 25.6 \\
\hline Total & 465 & \\
\hline Did not Respond & 14 & \\
\hline \hline Race & $\mathrm{n}$ & $\%$ \\
\hline White & 354 & 75.5 \\
\hline Other Race & 111 & 23.7 \\
\hline Total & 469 & \\
\hline Did not Respond & 10 & \\
\hline \hline
\end{tabular}


Figure 2: Respondent Demographics

$\mathrm{N}=479$
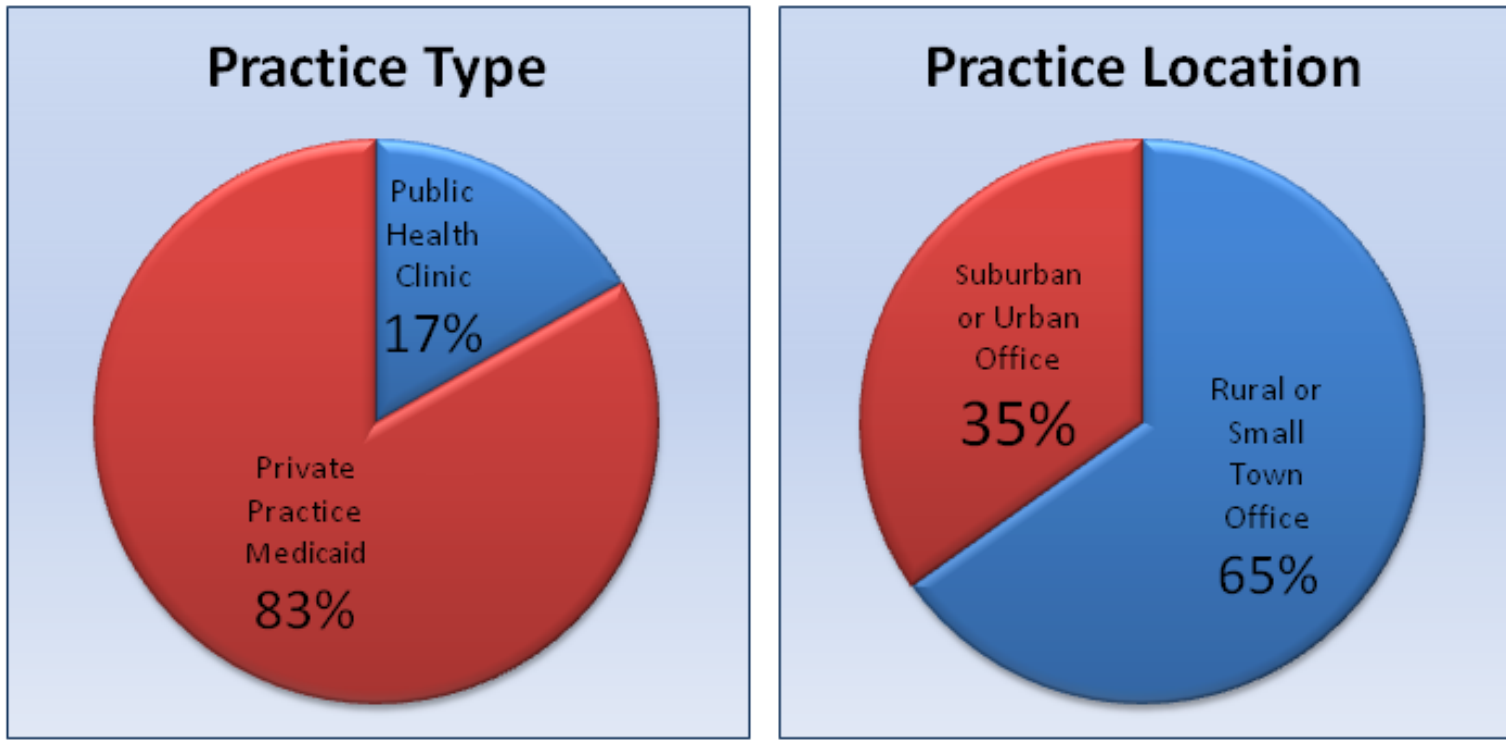

\section{Year of Graduation}

1999 or Earlier

$72 \%$

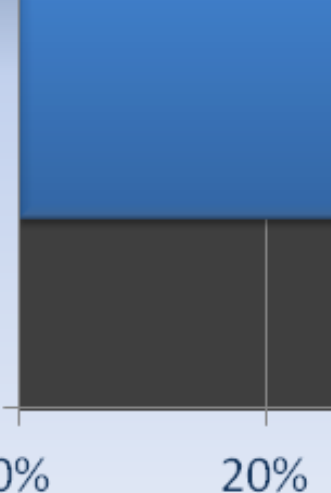

$20 \%$

$40 \%$
$2000-2011$

$28 \%$

$0 \%$

$60 \%$

$80 \%$

$100 \%$ 
Table 2: Logistic Regression - Respondent Demographics

\begin{tabular}{|c|c|c|c|c|c|}
\hline Variable of Interest & Associated Variables & Sig & $\operatorname{Exp}(B)$ & Lower 95\% CI & Upper 95\% CI \\
\hline \multicolumn{6}{|l|}{ PH vs Private ${ }^{1)}$} \\
\hline & Grad $\mathrm{Yr}^{33}$ & .051 & 1.742 & .998 & 3.040 \\
\hline & School $^{5)}$ & $.000^{*}$ & .293 & .170 & .505 \\
\hline & Gender $^{4)}$ & $.001 *$ & 2.66 & 1.52 & 4.61 \\
\hline \multicolumn{6}{|l|}{ Prac Location $^{2)}$} \\
\hline & School $^{5)}$ & $.014 *$ & 1.676 & 1.110 & 2.531 \\
\hline \multicolumn{6}{|l|}{ Grad $\mathrm{Yr}^{3)}$} \\
\hline & Gender $^{4)}$ & $.001^{*}$ & 2.303 & 1.432 & 3.703 \\
\hline & Race $^{6)}$ & $.003 *$ & 2.112 & 1.298 & 3.436 \\
\hline
\end{tabular}

(Controlled for practice type, practice location, graduation year, dental school, completion of advanced training, gender and race)

1) Public Health Clinic (PHC) vs Private Practice that Accepts Medicaid (PPM)

2) Rural or Small Town vs Suburban or Urban

3) Grads 2000 and later vs Grads 1999 or earlier

${ }^{4)}$ Female vs Male

5) UNC Graduates vs Grads from another dental school

6) Other Race vs White/Caucasian

${ }^{*} \mathrm{p}<0.5$ 
Table 3: Respondent Percentages - Conditions and Procedures $\quad \mathrm{N}=479$

\begin{tabular}{|c|c|c|c|c|c|c|}
\hline \multicolumn{7}{|c|}{$\begin{array}{l}\text { Q: How often patients have presented to your office with the following endodontic conditions on } \\
\text { restorable teeth in the past } 12 \text { months. }\end{array}$} \\
\hline \multirow[t]{2}{*}{ Condition } & \multicolumn{2}{|c|}{$\begin{array}{l}\text { Frequently (at least } \\
\text { once per month) }\end{array}$} & \multicolumn{2}{|c|}{$\begin{array}{l}\text { Rarely to } \\
\text { never }\end{array}$} & \multirow{2}{*}{$\begin{array}{r}\text { Total } \\
n\end{array}$} & \multirow{2}{*}{$\begin{array}{l}\begin{array}{l}\text { Did not } \\
\text { Respond }\end{array} \\
\mathrm{n}\end{array}$} \\
\hline & $\mathrm{n}$ & $\%$ & $\mathrm{n}$ & $\%$ & & \\
\hline Caries to the pulp & 374 & 78.7 & 101 & 21.3 & 475 & 4 \\
\hline Irreversible pulpitis & 359 & 76.1 & 113 & 23.9 & 472 & 7 \\
\hline Necrotic pulp & 333 & 70.3 & 141 & 29.7 & 474 & 5 \\
\hline Periapical abscess or sinus tract & 313 & 66.0 & 161 & 34.0 & 474 & 5 \\
\hline Non-healing previous RCT & 91 & 19.6 & 373 & 80.4 & 464 & 15 \\
\hline Trauma involving the pulp & 139 & 29.6 & 331 & 70.4 & 470 & 9 \\
\hline Other endodontic condition & 14 & 10.7 & 117 & 89.3 & 131 & 348 \\
\hline \multicolumn{7}{|c|}{ Q: How often you have performed the following Endodontic procedures in the past 12 months. } \\
\hline Procedure & $\begin{array}{l}\text { Frequen } \\
\text { once pe }\end{array}$ & least & $\begin{array}{l}\text { Rare } \\
\text { Neve }\end{array}$ & & Total & $\begin{array}{l}\text { Did not } \\
\text { Respond }\end{array}$ \\
\hline & $\mathrm{n}$ & $\%$ & $\mathrm{n}$ & $\%$ & $\mathrm{n}$ & $\mathrm{n}$ \\
\hline Direct Pulp Cap & 205 & 43.9 & 262 & 56.1 & 467 & 12 \\
\hline Indirect Pulp Cap & 279 & 59.7 & 188 & 40.3 & 467 & 12 \\
\hline Pulpotomy & 162 & 34.8 & 303 & 65.2 & 465 & 14 \\
\hline Pulpal Debridement & 105 & 23.1 & 349 & 76.9 & 454 & 25 \\
\hline $\begin{array}{l}\text { Partial Pulpotomy for } \\
\text { Apexogenesis }\end{array}$ & 14 & 3.0 & 447 & 97.0 & 461 & 18 \\
\hline NSRCT - Anterior & 158 & 33.8 & 309 & 66.2 & 467 & 12 \\
\hline NSRCT - Premolar & 99 & 21.3 & 366 & 78.7 & 465 & 14 \\
\hline NSRCT - Molar & 81 & 17.4 & 384 & 82.6 & 465 & 14 \\
\hline Retreatment - Anterior & 10 & 2.2 & 453 & 97.8 & 463 & 16 \\
\hline Retreatment - Premolar & 6 & 1.3 & 457 & 98.7 & 463 & 16 \\
\hline Retreatment - Molar & 6 & 1.3 & 458 & 98.7 & 464 & 15 \\
\hline Apexification & 3 & 0.6 & 461 & 99.4 & 464 & 15 \\
\hline Apicoectomy & 2 & 0.4 & 461 & 99.6 & 463 & 16 \\
\hline Other Endodontic Procedure & 2 & 1.3 & 152 & 98.7 & 154 & 325 \\
\hline
\end{tabular}


Table 4: Respondent Percentages - Referrals $\quad \mathrm{N}=479$

\begin{tabular}{|c|c|c|c|c|c|c|}
\hline \multirow[t]{2}{*}{ Referral } & \multicolumn{2}{|c|}{$\begin{array}{l}\text { Frequently (at least } \\
\text { once per month) }\end{array}$} & \multicolumn{2}{|c|}{$\begin{array}{l}\text { Rarely to } \\
\text { Never }\end{array}$} & \multirow{2}{*}{$\begin{array}{r}\text { Total } \\
\mathrm{n}\end{array}$} & \multirow{2}{*}{$\begin{array}{c}\text { Did not Respond } \\
\mathrm{n}\end{array}$} \\
\hline & $n$ & $\%$ & $\mathrm{n}$ & $\%$ & & \\
\hline Local Endodontist & 109 & 23.3 & 358 & 74.7 & 467 & 12 \\
\hline Local General Dentist & 51 & 11.2 & 403 & 88.8 & 454 & 25 \\
\hline $\begin{array}{l}\text { Another provider in your } \\
\text { group }\end{array}$ & 37 & 8.3 & 410 & 91.7 & 447 & 32 \\
\hline Another office in your system & 10 & 2.3 & 432 & 97.7 & 442 & 37 \\
\hline UNC School of Dentistry & 40 & 8.7 & 418 & 91.3 & 458 & 21 \\
\hline Other Referral & 16 & 9.5 & 152 & 90.5 & 168 & 311 \\
\hline
\end{tabular}

Table 5: Respondent Percentages - Endodontic Techniques $\quad \mathrm{N}=479$

\begin{tabular}{|c|c|c|}
\hline \multicolumn{3}{|c|}{$\begin{array}{l}\text { Q: In the past } 12 \text { months, which techniques or materials have you used for endodontic treatment } \\
\text { performed on patients who use Medicaid/Health Choice or other public health dental services? } \\
\text { (Multiple answer) }\end{array}$} \\
\hline Endodontic Technique & $\mathrm{n}$ & $\%$ \\
\hline Hand filing only & 124 & 25.9 \\
\hline Rotary filing only & 92 & 19.2 \\
\hline Combination hand and rotary filing & 209 & 43.6 \\
\hline Apex locator & 195 & 40.7 \\
\hline Digital X-ray & 248 & 51.8 \\
\hline Ultrasonic & 37 & 7.7 \\
\hline Lateral Condensation & 195 & 40.7 \\
\hline Warm Vertical Condensation & 60 & 12.5 \\
\hline Thermoplastic techniques - Obtura, System B elements, Calamus, etc & 54 & 11.3 \\
\hline Carrier based obturation - Thermafil, Realseal, etc & 104 & 21.7 \\
\hline Mineral Trioxide Aggregate - MTA & 41 & 8.6 \\
\hline Other & 19 & 4.0 \\
\hline None of the Above & 104 & 21.7 \\
\hline Total & 471 & \\
\hline Did not Respond & 8 & \\
\hline
\end{tabular}


Table 6: Logistic Regression - Conditions, Procedures, Referrals, Endodontic Techniques

\begin{tabular}{|c|c|c|c|c|c|}
\hline Conditions & Associated Variables & Sig & $\operatorname{Exp}(B)$ & Lower 95\% CI & Upper 95\% CI \\
\hline \multicolumn{6}{|c|}{ Caries to the Pulp } \\
\hline & PH vs Private ${ }^{1)}$ & $.002 *$ & 4.725 & 1.802 & 12.390 \\
\hline & Prac Location ${ }^{2)}$ & $.040 *$ & 1.686 & 1.025 & 2.773 \\
\hline & Grad Yr $(2000+)^{3)}$ & .055 & 1.80 & .987 & 3.268 \\
\hline \multicolumn{6}{|c|}{ Irreversible Pulpitis } \\
\hline & PH vs Private $^{1)}$ & $.011^{*}$ & 2.740 & 1.265 & 5.931 \\
\hline & Prac Location $^{2)}$ & $.022 *$ & 1.747 & 1.083 & 2.818 \\
\hline & Grad Yr $(2000+)^{3)}$ & $.005 *$ & 2.34 & 1.294 & 4.237 \\
\hline \multicolumn{6}{|l|}{ Necrotic Pulp } \\
\hline & PH vs Private ${ }^{1)}$ & $.021 *$ & 2.152 & 1.124 & 4.120 \\
\hline & Grad Yr $(2000+)^{3)}$ & $.031 *$ & 1.754 & 1.054 & 2.915 \\
\hline \multicolumn{6}{|c|}{ PA Abscess or APST } \\
\hline & $\mathrm{PH}_{\text {vs }}$ Private $^{1)}$ & $.004^{*}$ & 2.570 & 1.364 & 4.843 \\
\hline Procedures & Associated Variables & Sig & $\operatorname{Exp}(B)$ & Lower 95\% CI & Upper 95\% CI \\
\hline \multicolumn{6}{|c|}{ Indirect Pulp Cap } \\
\hline & PH vs Private ${ }^{1)}$ & $.001 *$ & 2.836 & 1.540 & 5.226 \\
\hline & Grad Yr $(2000+)^{3)}$ & $.009 *$ & 1.835 & 1.163 & 2.817 \\
\hline Pulpotomy & PH vs Private ${ }^{1)}$ & $.001 *$ & 2.468 & 1.436 & 4.241 \\
\hline & Grad Yr $(2000+)^{3)}$ & $.000^{*}$ & 2.283 & 1.451 & 3.584 \\
\hline \multicolumn{6}{|c|}{ Pulpal Debridement } \\
\hline & PH vs Private ${ }^{1)}$ & $.048 *$ & 1.803 & 1.005 & 3.232 \\
\hline \multicolumn{6}{|l|}{ RCT Anterior } \\
\hline & PH vs Private ${ }^{1)}$ & .13 & 1.51 & .89 & 2.58 \\
\hline & Grad Yr $(2000+)^{3)}$ & $.000 *$ & 3.106 & 2.012 & 4.808 \\
\hline \multicolumn{6}{|l|}{ RCT Premolar } \\
\hline & PH vs Private ${ }^{1)}$ & $.009 *$ & 2.207 & 1.215 & 4.009 \\
\hline & Prac Location ${ }^{2)}$ & $.029 *$ & 1.830 & 1.064 & 3.148 \\
\hline & Grad Yr $(2000+)^{3)}$ & $.000 *$ & 3.311 & 1.996 & 5.495 \\
\hline \multicolumn{6}{|l|}{ RCT Molar } \\
\hline & PH vs Private ${ }^{1)}$ & .63 & 1.18 & .61 & 2.27 \\
\hline & Grad Yr $(2000+)^{3)}$ & $.000^{*}$ & 2.967 & 1.751 & 5.025 \\
\hline Referrals & Associated Variables & Sig & $\operatorname{Exp}(B)$ & Lower 95\% CI & Upper 95\% CI \\
\hline \multicolumn{6}{|c|}{ Local Endodontist } \\
\hline & PH vs Private ${ }^{1)}$ & $.000^{*}$ & 3.284 & 1.868 & 5.773 \\
\hline & Grad Yr $(2000+)^{3)}$ & $.02 *$ & 1.76 & 1.09 & 2.85 \\
\hline \multicolumn{6}{|l|}{ UNC } \\
\hline & PH vs Private ${ }^{1)}$ & $.012 *$ & 2.671 & 1.245 & 5.730 \\
\hline & Grad Yr $(2000+)^{3)}$ & $.01^{*}$ & 2.55 & 1.24 & 5.23 \\
\hline Techniques & Associated Variables & Sig & $\operatorname{Exp}(B)$ & Lower 95\% CI & Upper 95\% CI \\
\hline \multicolumn{6}{|c|}{ Combination Hand/Rotary } \\
\hline & PH vs Private ${ }^{1)}$ & .54 & .85 & .50 & 1.44 \\
\hline & Grad Yr $(2000+)^{3)}$ & $.000 *$ & 2.833 & 1.838 & 4.365 \\
\hline \multicolumn{6}{|l|}{ Apex Locator } \\
\hline & PH vs Private ${ }^{1)}$ & .85 & .95 & .56 & 1.61 \\
\hline & Grad Yr $(2000+)^{3)}$ & $.000 *$ & 2.735 & 1.781 & 4.199 \\
\hline \multicolumn{6}{|l|}{ Digital Xray } \\
\hline & PH vs Private ${ }^{1)}$ & .106 & .640 & .372 & 1.100 \\
\hline & Grad Yr $(2000+)^{3)}$ & $.000 *$ & 4.443 & 2.757 & 7.160 \\
\hline \multicolumn{6}{|c|}{ Thermoplastic Techniques } \\
\hline & PH vs Private ${ }^{1)}$ & .98 & 1.01 & .47 & 2.16 \\
\hline & Grad Yr $(2000+)^{3)}$ & $.035 *$ & 1.919 & 1.047 & 3.519 \\
\hline \multicolumn{6}{|l|}{ No Techniques } \\
\hline & Grad Yr (2000+) & $.000 *$ & .320 & .170 & .601 \\
\hline
\end{tabular}

(Controlled for practice type, practice location, graduation year, dental school, completion of advanced training, gender and race)

${ }^{1)}$ Public Health Location vs Private Practice that Accepts Medicaid (PPM)

${ }^{2)}$ Rural or Small Town vs Suburban or Urban

${ }^{3)}$ Grads 2000 and later vs Grads 1999 or earlier

${ }^{*} \mathrm{p}<.05$ 
Table 7: Respondent Percentages - Barriers $\quad \mathrm{N}=479$

\begin{tabular}{|c|c|c|c|c|c|c|}
\hline \multirow[t]{2}{*}{ Barrier } & \multicolumn{2}{|c|}{$\begin{array}{l}\text { Moderate or } \\
\text { Major Barrier }\end{array}$} & \multicolumn{2}{|c|}{$\begin{array}{l}\text { Not a Major } \\
\text { Barrier }\end{array}$} & \multirow{2}{*}{$\begin{array}{c}\text { Total } \\
n\end{array}$} & \multirow{2}{*}{$\begin{array}{c}\begin{array}{l}\text { Did not } \\
\text { Respond }\end{array} \\
\mathrm{n}\end{array}$} \\
\hline & $\mathrm{n}$ & $\%$ & $\mathrm{n}$ & $\%$ & & \\
\hline Cost of Endodontic Treatment & 403 & 87.4 & 58 & 12.6 & 461 & 18 \\
\hline Cost of final restoration & 395 & 85.5 & 67 & 14.5 & 462 & 17 \\
\hline Lack of Insurance & 405 & 89.2 & 49 & 10.8 & 454 & 25 \\
\hline $\begin{array}{l}\text { Lack of endodontists or general dentists } \\
\text { who will accept the patients' insurance }\end{array}$ & 374 & 80.4 & 91 & 19.6 & 465 & 14 \\
\hline $\begin{array}{l}\text { Lack of local endodontists or general } \\
\text { dentists who will provide treatment }\end{array}$ & 319 & 68.8 & 145 & 31.3 & 464 & 15 \\
\hline $\begin{array}{l}\text { Lack of adequate training in dental school to } \\
\text { perform RCT }\end{array}$ & 75 & 16.3 & 386 & 83.7 & 461 & 18 \\
\hline $\begin{array}{l}\text { Transportation - Difficulty for patients to } \\
\text { travel to another location/city for treatment }\end{array}$ & 201 & 43.2 & 264 & 56.8 & 465 & 14 \\
\hline Language or culture differences & 84 & 18.2 & 377 & 81.8 & 461 & 18 \\
\hline $\begin{array}{l}\text { Dental IQ - Pts do not have an appreciation } \\
\text { for maintaining their natural teeth }\end{array}$ & 318 & 68.1 & 149 & 31.9 & 467 & 12 \\
\hline $\begin{array}{l}\text { Dental History - Pts have had other } \\
\text { extractions in the past }\end{array}$ & 301 & 64.7 & 164 & 35.3 & 465 & 14 \\
\hline Fear - Pts are afraid of receiving RCT & 270 & 56.4 & 197 & 42.2 & 467 & 12 \\
\hline Pt preference - pts prefer an ext to a RCT & 293 & 62.7 & 174 & 37.3 & 467 & 12 \\
\hline
\end{tabular}


Table 8: Logistic Regression - Barriers

\begin{tabular}{|c|c|c|c|c|c|}
\hline Barriers & Associated Variables & Sig & $\operatorname{Exp}(B)$ & Lower 95\% CI & Upper 95\% CI \\
\hline \multicolumn{6}{|c|}{ Cost - Endo Tx } \\
\hline & PH vs Private ${ }^{1)}$ & $.033^{*}$ & .490 & .254 & .943 \\
\hline \multicolumn{6}{|c|}{ Cost - Restoration } \\
\hline & none & & & & \\
\hline \multicolumn{6}{|c|}{ Lack of Insurance } \\
\hline & PH vs Private $^{1)}$ & $.022 *$ & .435 & .214 & .886 \\
\hline & Grad Yr $(2000+)^{3)}$ & $.045^{*}$ & 2.288 & 1.020 & 5.12 \\
\hline \multicolumn{6}{|c|}{ Endo no accept Ins } \\
\hline & None & & & & \\
\hline \multicolumn{6}{|c|}{ No endodontists in area } \\
\hline & None & & & & \\
\hline \multicolumn{6}{|c|}{ Lack of Training } \\
\hline & Gender $^{4)}$ & $.022 *$ & 1.89 & 1.098 & 3.217 \\
\hline \multicolumn{6}{|c|}{ Transportation } \\
\hline & PH vs Private $^{1)}$ & $.001^{*}$ & 2.624 & 1.505 & 4.573 \\
\hline & Prac Location $^{2)}$ & $.003^{*}$ & 1.917 & 1.240 & 2.964 \\
\hline \multicolumn{6}{|l|}{ Language } \\
\hline & PH vs Private ${ }^{1)}$ & $.000^{*}$ & 3.177 & 1.779 & 5.673 \\
\hline \multicolumn{6}{|l|}{ Dental IQ } \\
\hline & Prac Location $^{2)}$ & $.034^{*}$ & 1.580 & 1.034 & 2.413 \\
\hline \multicolumn{6}{|c|}{ Dental History } \\
\hline & PH vs Private ${ }^{1)}$ & .051 & 1.762 & .999 & 3.108 \\
\hline & Prac Location $^{2)}$ & $.025 *$ & 1.596 & 1.060 & 2.403 \\
\hline \multicolumn{6}{|l|}{ Fear } \\
\hline & None & & & & \\
\hline \multicolumn{6}{|c|}{ Pt Preference } \\
\hline & PH vs Private ${ }^{1)}$ & $.001^{*}$ & 3.016 & 1.617 & 5.627 \\
\hline & Prac Location $^{2)}$ & $.011^{*}$ & 1.702 & 1.129 & 2.566 \\
\hline
\end{tabular}

(Controlled for practice type, practice location, graduation year, dental school, completion of advanced training, gender and race)

1) Public Health Location vs Private Practice that Accepts Medicaid (PPM)

2) Rural or Small Town vs Suburban or Urban

3) Grads 2000 and later vs Grads 1999 or earlier

4) Female vs Male

${ }^{*} \mathrm{p}<.05$ 


\section{Survey Instrument} UNIVERSITY OF NC SCHOOL OF DENTISTRY
DEPARTMENT OF ENDODONTICS
ID:

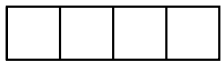

Access to Endodontic Care in North Carolina Public Health and Medicaid Settings

Thank you for your interest in this survey regarding access to endodontic care in North Carolina dental public health and Medicaid settings. By completing and returning this survey you are indicating your consent to participate in this research project. You may withdraw your consent and stop participation at any time, without penalty.

Please use a BLACK BALLPOINT PEN to complete the survey. Choose only ONE response per question unless otherwise indicated. Fill in circles completely or fill in the boxes and blanks as needed.

When completed, please place the survey in the enclosed business reply envelope and mail it back to us. Thank you again for your participation.

1. Does your practice accept any of the following payment plans? (Mark all that apply)

Medicaid

$\mathrm{NC}$ Health Choice

Sliding fee schedule based on income

Please indicate which of the following procedures are included in the sliding fee schedule? (Mark all that apply)

O D3220 Pulpotomy

O D3221 Pulpal Debridement

O D3310 Non Surgical Root Canal - Anterior

O D3320 Non Surgical Root Canal - Premolar

D3330 Non Surgical Root Canal - Molar

$\bigcirc$ None of the above are on the sliding fee scale

None of the above

Please answer the following questions as they pertain to your patients who use Medicaid/NC Health Choice, Sliding fee schedules or other public health dental services.

2. For patients who use Medicaid/Health Choice or other public health dental services, please indicate how often patients have presented to your office with the following endodontic conditions on restorable teeth in the past 12 months. PLEASE CONSIDER PERMANENT TEETH ONLY.

\begin{tabular}{|c|c|c|c|c|}
\hline & $\begin{array}{l}\text { At least } \\
\text { once per } \\
\text { week }\end{array}$ & $\begin{array}{l}\text { At least } \\
\text { once per } \\
\text { month }\end{array}$ & $\begin{array}{l}\text { Less than } \\
\text { once per } \\
\text { month }\end{array}$ & Never \\
\hline Caries to the pulp & 0 & 0 & 0 & 0 \\
\hline Irreversible pulpitis & 0 & O & 0 & O \\
\hline Necrotic Pulp & O & O & O & O \\
\hline Periapical abscess or sinus tract & O & O & O & O \\
\hline Non-healing previous root canal treatment & 0 & O & 0 & O \\
\hline Trauma involving the pulp & $\mathrm{O}$ & $\mathrm{O}$ & $\mathrm{O}$ & $\bigcirc$ \\
\hline Other Endodontic Condition (please specify) & $\mathrm{O}$ & 0 & 0 & 0 \\
\hline
\end{tabular}


ID:

3. For patients who use Medicaid/Health Choice or other public health dental services, please indicate how often you have performed the following Endodontic procedures in the past 12 months. PLEASE CONSIDER PERMANENT TEETH ONLY.

\begin{tabular}{|c|c|c|c|c|}
\hline & $\begin{array}{l}\text { At least } \\
\text { once per } \\
\text { week }\end{array}$ & $\begin{array}{l}\text { At least } \\
\text { once per } \\
\text { month }\end{array}$ & $\begin{array}{l}\text { Less than } \\
\text { once per } \\
\text { month }\end{array}$ & Never \\
\hline D3110 Direct Pulp Cap & O & O & O & $\bigcirc$ \\
\hline D3120 Indirect Pulp Cap & O & O & O & O \\
\hline D3220 Pulpotomy & $\bigcirc$ & O & $\bigcirc$ & O \\
\hline D3221 Pulpal Debridement & O & 0 & $\bigcirc$ & O \\
\hline D3222 Partial Pulpotomy for Apexogenesis & $\bigcirc$ & $\bigcirc$ & $\bigcirc$ & $\bigcirc$ \\
\hline D3310 Non Surgical Root Canal - Anterior & $\bigcirc$ & $\bigcirc$ & $\bigcirc$ & $\bigcirc$ \\
\hline D3320 Non Surgical Root Canal - Premolar & $\bigcirc$ & O & $\bigcirc$ & $\bigcirc$ \\
\hline D3330 Non Surgical Root Canal - Molar & O & $\mathrm{O}$ & $\bigcirc$ & $\mathrm{O}$ \\
\hline D3346 Endodontic Retreatment - Anterior & $\bigcirc$ & $\bigcirc$ & $\bigcirc$ & $\bigcirc$ \\
\hline D3347 Endodontic Retreatment - Premolar & $\bigcirc$ & $\bigcirc$ & $\bigcirc$ & $\bigcirc$ \\
\hline D3348 Endodontic Retreatment - Molar & 0 & O & $\bigcirc$ & O \\
\hline D3351-D3353 Apexification & 0 & O & $\bigcirc$ & O \\
\hline D3410-D3425 Apicoectomy & O & $\mathrm{O}$ & O & $\mathrm{O}$ \\
\hline $\begin{array}{l}\text { Other Endodontic Procedure } \\
\text { (please specify) }\end{array}$ & 0 & 0 & $\bigcirc$ & $\bigcirc$ \\
\hline
\end{tabular}

4. In the past $\mathbf{1 2}$ months, how often have you referred patients who use Medicaid/Health Choice or other public health dental services, for endodontic care to any of the following? .

\begin{tabular}{|c|c|c|c|c|}
\hline & $\begin{array}{l}\text { At least } \\
\text { once per } \\
\text { week }\end{array}$ & $\begin{array}{l}\text { At least } \\
\text { once per } \\
\text { month }\end{array}$ & $\begin{array}{l}\text { Less than } \\
\text { once per } \\
\text { month }\end{array}$ & Never \\
\hline Local Endodontist & $\mathrm{O}$ & O & $\mathrm{O}$ & $\bigcirc$ \\
\hline Local General Dentist & $\mathrm{O}$ & $\mathrm{O}$ & $\mathrm{O}$ & $\mathrm{O}$ \\
\hline Another provider in your group & $\bigcirc$ & $\mathrm{O}$ & $\bigcirc$ & $\bigcirc$ \\
\hline Another office in your clinic system & $\bigcirc$ & $\bigcirc$ & $\bigcirc$ & $\bigcirc$ \\
\hline UNC School of Dentistry & O & $\bigcirc$ & O & $\mathrm{O}$ \\
\hline Other Referral (please specify) & 0 & 0 & 0 & 0 \\
\hline
\end{tabular}


5. In the past 12 months, which techniques or materials have you used for endodontic treatment performed on patients who use Medicaid/Health Choice or other public health dental services? (Mark all that apply)
Hand filing only
Rotary filing only
Combination hand and rotary filing
Apex locator
D Digital Xray
O Ultrasonic
Lateral Condensation
Warm Vertical Condensation
$\bigcirc$ Thermoplastic techniques - Obtura, System B elements, Calamus etc
Carrier Based Obturation - Thermafil, RealSeal One, etc
Mineral Trioxide Aggregate - MTA
$\bigcirc$ Other (please specify)
None of the above

6. Please indicate whether you feel the following conditions pose a barrier to access to endodontic care for your patients who use Medicaid/Health Choice or other public health dental services.

\begin{tabular}{|c|c|c|c|c|c|}
\hline Cost of endodontic treatment & $\begin{array}{c}\text { Significant } \\
\text { barrier } \\
\bigcirc\end{array}$ & $\begin{array}{c}\text { Moderate } \\
\text { barrier } \\
\bigcirc\end{array}$ & $\begin{array}{l}\text { Mild } \\
\text { barrier } \\
\bigcirc\end{array}$ & $\begin{array}{l}\text { Not a } \\
\text { barrier } \\
\bigcirc\end{array}$ & $\begin{array}{c}\text { No } \\
\text { opinion } \\
\bigcirc\end{array}$ \\
\hline Cost of final restoration following endodontic treatment & $\bigcirc$ & $\bigcirc$ & O & $\bigcirc$ & $\bigcirc$ \\
\hline Lack of insurance & $\bigcirc$ & $\bigcirc$ & $\bigcirc$ & $\bigcirc$ & ○ \\
\hline $\begin{array}{l}\text { Lack of endodontists or general dentists who will accept the } \\
\text { patients' insurance }\end{array}$ & $\bigcirc$ & $\bigcirc$ & $\bigcirc$ & $\bigcirc$ & $\bigcirc$ \\
\hline $\begin{array}{l}\text { Lack of local endodontists or general dentists who will provide } \\
\text { treatment }\end{array}$ & $\bigcirc$ & $\bigcirc$ & $\bigcirc$ & $\bigcirc$ & $\bigcirc$ \\
\hline $\begin{array}{l}\text { Lack of adequate training in dental school to perform root canal } \\
\text { treatments }\end{array}$ & O & O & O & O & O \\
\hline $\begin{array}{l}\text { Transportation - Difficulty for patients to travel to another } \\
\text { location/city for treatment }\end{array}$ & $\bigcirc$ & $\bigcirc$ & $\bigcirc$ & $\bigcirc$ & $\bigcirc$ \\
\hline Language or culture differences & O & $\bigcirc$ & O & $\bigcirc$ & $\bigcirc$ \\
\hline $\begin{array}{l}\text { Dental IQ - Patients do not have an appreciation for maintaining } \\
\text { their natural teeth }\end{array}$ & $\bigcirc$ & $\bigcirc$ & $\bigcirc$ & $\bigcirc$ & $\bigcirc$ \\
\hline Dental History - Patients have had other extractions in the past & $\bigcirc$ & $\bigcirc$ & $\bigcirc$ & $\bigcirc$ & $\bigcirc$ \\
\hline Fear - Patients are afraid of receiving a root canal treatment & $\bigcirc$ & $\bigcirc$ & O & $\bigcirc$ & $\bigcirc$ \\
\hline $\begin{array}{l}\text { Patient preference - patients prefer to receive an extraction } \\
\text { rather than a root canal treatment }\end{array}$ & $\bigcirc$ & $\bigcirc$ & $\bigcirc$ & 0 & 0 \\
\hline
\end{tabular}




\title{
7. What best describes your practice type? (Mark all that apply)
}
Public health clinic/office
Community Dental Center or Health Center
Private practice - solo practice
Private practice - group practice

Special Care Health Center - Women \& Children, Migrant care, HIV clinic, Homeless Shelter, etc

Other (please specify)

8. What best describes your practice location?
Rural location
Small town location
Suburban location
Urban location
Other (please specify)

9. How many hours per week do you usually work at this clinic/office?

$\bigcirc$ Less than 8 hours $\bigcirc 8-20$ hours $\bigcirc 20-40$ hours $\bigcirc$ More than 40 hours

10. Please estimate the percentage of pediatric patients you treat at this clinic/office?
$O$ Less than $25 \%$ of my patients are children
26-50\% of my patients are children
51-75\% of my patients are children
More than $75 \%$ of my patients are children

11. What year did you graduate from Dental School? (DDS/DMD or equivalent)

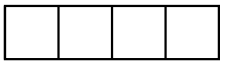

\section{From which dental school did you graduate? (DDS/DMD or equivalent)}
UNC School of Dentistry
Other (please specify)

13. Have you earned a residency/graduate program certificate or degree? (Mark all that apply)
None
Advanced General Dentistry (AEGD)
$\bigcirc$ General Practice Residency (GPR)
Public Health
$\bigcirc$ Endodontics
$\bigcirc$ Other (please sepcify)

14. What is your age?

15. What is your gender? $\bigcirc$ Male $\bigcirc$ Female

16. What is your race? (Mark all that apply)
Multi-racial
Asian/Pacific Islander
Black
White

$\bigcirc$ Other (please specify)

We thank you for your time spent taking this survey.

Please return the survey in the enclosed postage paid envelope or mail directly to

\author{
Steven Richardson DMD \\ Department of Endodontics \\ UNC School of Dentistry \\ 1098 Old Dental Bldg, CB \# 7450 \\ Chapel Hill, NC 27599-7450
}




\section{References:}

1. U.S. Department of Health and Human Services. Oral Health in America: A Report of the Surgeon General. Rockville, MD: U.S. Department of Health and Human Services, National Institute of Dental and Craniofacial Research, National Institutes of Health, 2000. 2000.

2. Discepolo K, Kaplan AS. The patient protection and affordable care act: effects on dental care. N Y State Dent J 2011;77(5):34-38.

3. ADA. Breaking down barriers to oral health for all Americans: the role of workforce. J Calif Dent Assoc 2011;39(7):491-502.

4. ADA. Breaking Down Barriers to Oral Health for All Americans: Repairing the Tattered Safety Net. A Statement from the American Dental Association 2011.

5. Guay AH. Access to dental care: solving the problem for underserved populations. J Am Dent Assoc 2004;135(11):1599-1605; quiz 1623.

6. Vargas CM, Arevalo O. How dental care can preserve and improve oral health. Dent Clin North Am 2009;53(3):399-420.

7. Rule JT, Welie JV. The dilemma of access to care: symptom of a systemic condition. Dent Clin North Am 2009;53(3):421-433.

8. Chen CY, Hasselgren G, Serman N, Elkind MS, Desvarieux M, Engebretson SP. Prevalence and quality of endodontic treatment in the Northern Manhattan elderly. J Endod 2007;33(3):230-234.

9. Manski RJ, Moeller JF. Use of dental services: an analysis of visits, procedures and providers, 1996. J Am Dent Assoc 2002;133(2):167-175.

10. Rhodes KV, Bisgaier J. Limitations in access to dental and medical specialty care for publicly insured children. LDI Issue Brief 2011;16(7):1-4.

11. Sharpe G, Durham JA, Preshaw PM. Attitudes regarding specialist referrals in periodontics. Br Dent J 2007;202(4):E11; discussion 218-219.

12. Glickman GN. Access to Care: Bridging the Gap. Journal of Endodontics 2009;35(8):1163.

13. Gehshan S, Snyder A. Why public policy matters in improving access to dental care. Dent Clin North Am 2009;53(3):573-589.

14. Nash DA. Improving access to oral health care for children by expanding the dental workforce to include dental therapists. Dent Clin North Am 2009;53(3):469-483.

15. Colangelo GA. Innovations to improve oral health care access. Dent Clin North Am 2009;53(3):591-608.

16. CMS. Innovative State Practices for Improving the Provision of Medicaid Dental Services: Summary of Eight State Reports: (Alabama, Arizona, Maryland, Nebraska, North Carolina, Rhode Island, Texas and Virginia). Centers for Medicare \& Medicaid Services (CMS); 2011. 
17. ADA. State Innovations to Improve Access to Oral Health Care for Low Income Children: A Compendium Update. Chicago: American Dental Association 2005.

18. Edelstein BL. Putting teeth in CHIP: 1997-2009 retrospective of congressional action on children's oral health. Acad Pediatr 2009;9(6):467-475.

19. Clarke JH. Toothaches and death. J Hist Dent 1999;47(1):11-13.

20. Aldous JA, Powell GL, Stensaas SS. Brain abscess of odontogenic origin: report of case. J Am Dent Assoc 1987;115(6):861-863.

21. AAE. AAE Position Statement - Access to Care. Chicago, IL; 2010.

22. Kressin NR, Boehmer U, Berlowitz D, Christiansen CL, Pitman A, Jones JA. Racial variations in dental procedures: the case of root canal therapy versus tooth extraction. Med Care 2003;41(11):1256-1261.

23. Sweet M, Damiano P, Rivera E, Kuthy R, Heller K. A comparison of dental services received by Medicaid and privately insured adult populations. J Am Dent Assoc 2005;136(1):93-100.

24. Morris. Access to Care and Endodontics: Treatment Rendered in Public Health Clinics. Journal of Endodontics 2009;36(3):572.

25. Dillman DA. Mail and internet surveys : the tailored design method. 2nd ed. Hoboken, N.J.: Wiley; 2007.

26. HRSA. Oral Health Workforce. 2012 [cited 2012 2/23/2012]; Available from: http://www.hrsa.gov/publichealth/clinical/oralhealth/workforce.html

27. Rozier RG, King RS. Defining the need for dental care in North Carolina: contributions of public health surveillance of dental diseases and conditions. N C Med J 2005;66(6):438-444.

28. NCDHHS. North Carolina Department of Health and Human Services - Division of Medical Assistance. [cited 2012 February 2012]; Available from:

29. McGinn-Shapiro M. Medicaid Coverage of Adult Dental Services. State Health Policy Monitor 2008;2(2).

30. Bjorndal L. Indirect pulp therapy and stepwise excavation. J Endod 2008;34(7 Supl):S29-33.

31. AAE. American Association of Endodontists: Endodontic Facts. 2012.

32. ADA. Breaking Down Barriers to Oral health for All Americans: Repairing the Tattered Safety Net. American Dental Association 2011.

33. Borchgrevink A, Snyder A, Gehshan S. The Effects of Medicaid Reimbursement Rates on Access to Dental Care. National Academy for State Health Policy 2008.

34. Fulton J, Hughes J, Mercer C. The Life Cycle of Human Teeth. In. Chapel Hill, NC: Department of Epidemiology, School of Public Health, University of North Carolina; 1964. 